\title{
Çok bantlı görüntülerde pan-keskinleștirme üzerine bir inceleme
}

\author{
A review on pansharpening of multispectral images
}

\author{
Çiğdem ŞERİFOĞLU YILMAZ ${ }^{* 1, a}$, Volkan YILMAZ ${ }^{2, b}$, Oğuz GÜNGÖR ${ }^{3, c}$ \\ ${ }^{I}$ Karadeniz Teknik Üniversitesi, Mühendislik Fakültesi, Harita Mühendisliği Bölümü, 61080, Trabzon \\ ${ }^{2}$ Artvin Çoruh Üniversitesi, Mühendislik Fakültesi, Harita Mühendisliği Bölümü, 08100, Artvin \\ ${ }^{3}$ Ankara Üniversitesi, Fen Bilimleri Enstitüsü, Gayrimenkul Geliştirme ve Yönetimi Anabilim Dall, 06590, Ankara
}

\section{$\ddot{O} z$}

Uzaktan algılama uyduları, algılayıcılarındaki teknik kısıtlamalardan dolayı hem uzamsal detay kalitesi hem de spektral kalitesi yüksek görüntüler üretememektedir. Bu durum, kullanıcıları yüksek uzamsal çözünürlüklü çok bantlı görüntüler elde edebilme konusunda yeni arayışlar içine sokmaktadır. Pan-keskinleştirme işlemi bu probleme etkin bir çözüm sunmaktadır. Pan-keskinleştirme, yüksek uzamsal çözünürlüklü bir pankromatik görüntünün uzamsal detaylarının, yüksek spektral çözünürlüklü çok bantlı bir görüntüye aktarılarak uzamsal çözünürlüğü yüksek çok bantlı bir görüntü üretilmesi işlemidir. Literatürde pan-keskinleştirme için oldukça fazla sayıda yöntem geliştirilmiştir. Bu yöntemlerin her birinin kendine has avantaj ve dezavantajları vardır. Bu durum, kullanıcıları hangi durumda hangi yöntemin kullanılması gerektiği hususunda tereddüte düşürmektedir. Genel amacı, literatürdeki çeşitli konvansiyonel ve gelişmiş pankeskinleştirme yöntemleri hakkında teorik bilgiler vermek ve bu yöntemlerin hangi durumlarda kullanılabileceği hususunda analistlere yol göstermek olan bu çalışmanın, pan-keskinleştirme hakkında iyi bir rehber olacağı kanaatindeyiz. Çalışmada, ayrıca pan-keskinleştirilmiş görüntülerin spektral ve uzamsal detay kalitelerinin görsel ve sayısal olarak nasıl değerlendirilebileceği hakkında da bilgiler verilmiştir.

Anahtar kelimeler: Görüntü kaynaştırma, Pan-keskinleştirme, Sayısal görüntü işleme, Veri füzyonu

\begin{abstract}
Remote sensing satellites cannot produce images of high spatial detail quality and spectral quality due to technical limitations in their sensors, which forces users to find alternative ways to produce such images. Pan-sharpening offers an effective solution to this problem. Pan-sharpening aims to transfer the spatial details of a high-resolution panchromatic image into a high spectral resolution image, producing a multispectral image of high spatial resolution. A wide variety of pansharpening methods have been proposed in the litreture. Each pansharpening method has its own advantages and disadvantages. This situation makes users hesitant about which method should be used under what situation. We believe that this study, whose primary objective is to provide theoretical information about various conventional and state-of-the-art pan-sharpening methods in the literature, and to guide the analysts as to which pansharpening methods should be used under what circumstances, will be a good pan-sharpening guide. This study also provides information on how the spatial and spectral quality of pan-sharpened images may be evaluated qualitatively and quantitatively.
\end{abstract}

Keywords: Image fusion, Pan-sharpening, Digital image processing, Data fusion

\footnotetext{
*a Çiğdem ŞERİFŎLLU YILMAZ; cigdem_srf@hotmail.com, Tel: (0462) 37727 66, orcid.org/0000-0002-9738-5124

${ }^{\mathrm{b}}$ orcid.org/0000-0003-0685-8369 $\quad{ }^{\mathrm{c}}$ orcid.org/0000-0002-3280-5466
} 


\section{Giriş}

40 yıldan uzun bir süredir sürekli gelişen uydu teknolojileri sayesinde yeryüzünün istenilen sıklıkta ve yüksek doğrulukla görüntülenmesi mümkün olmaktadır. Uzaydaki yörüngelerinde seyreden uzaktan algılama uyduları tarafindan çekilen görüntüler çeşitli mühendislik uygulamalarında altlık olarak kullanılmaktadır. Çoğu durumda yersel ölçüm tekniklerine göre daha kısa zamanda ve daha az maliyette arazi kullanımı ve konum bilgisi sağladıklarından dolayı haritacılıktan madenciliğe, ormancılıktan şehir plancılığına birçok disiplin uydu görüntülerinden faydalanmaktadır (Kamir vd., 2020; Liu vd., 2020; Farwell vd., 2021; Wang vd., 2021; Khatancharoen vd., 2021).

Uzaktan algılama uydularının ürettiği görüntüler ile ilgili olarak iki önemli çözünürlükten söz edilebilir: uzamsal çözünürlük ve spektral çözünürlük. Uzamsal çözünürlük uydu görüntüsü üzerinde göz ile ayırt edilebilen en küçük nesnenin boyutuyla ilişkilidir. Diğer bir deyişle, uzamsal çözünürlük uydu görüntüsünün bir pikselinin alanının yeryüzündeki karşılığını temsil eder. Spektral çözünürlük ise yeryüzünden yansıyarak gelen elektromanyetik enerjinin kaydedildiği dalga boyu aralığının genişliği ile ilgilidir. Elektromanyetik enerji ne kadar dar ve fazla sayıda dalga boyu aralığında depolanıyorsa spektral çözünürlük o kadar fazladır. Bu nedenledir ki Hyperion, AVIRIS (Airborne Visible/Infrared Imaging Spectrometer) ve PROBA gibi uydular IKONOS, QuickBird, WorldView-I-II-III gibi uydulara göre daha fazla sayıda bant ve dolayisıyla daha yüksek spektral çözünürlükte görüntü sunmaktadir.
Günümüzde birçok mühendislik uygulaması uzamsal detay kalitesi ve spektral kalitesi yüksek görüntülere ihtiyaç duymaktadır. Ancak, uydu sensörlerinin sayısındaki artış görüntülerin bant sayılarını arttırmakta, bu da her bir sensöre düşen enerji miktarını azaltmaktadır. Bu enerji kaybının azaltılması için sensör boyutları büyütülmekte ve bu durum da görüntülerin uzamsal çözünürlügünü düşürmektedir. Uydulardaki bu teknik kısıtlamadan dolayı hem spektral çözünürlüğü hem de uzamsal çözünürlüğü yüksek görüntüler elde etmek her zaman mümkün olmamaktadır (Yilmaz ve Gungor, 2016a). Bu nedenle kullanicilar ya spektral kalitesi ya da uzamsal detay kalitesi yüksek görüntüler kullanabilmekte ve bunun doğal sonucu olarak ya renk kalitesinden ya da uzamsal detay kalitesinden feragat etmek zorunda kalmaktadırlar. Bu durum da kullanıcıları yüksek uzamsal detay içeriğine sahip çok bantlı görüntüler üretmeye yöneltmektedir. Pan-keskinleştirme bu tarz görüntüler üretmek için sıklıkla kullanılan bir yöntemdir.

Pan-keskinleştirmedeki temel amaç hem spektral kalitesi hem de uzamsal detay kalitesi yüksek olan çok bantlı görüntüler üretilmesidir (Yilmaz vd., 2020). Bu amaçla 1980' lerden günümüze kadar oldukça fazla sayıda pan-keskinleştirme yöntemi literatüre kazandırılmıştır. Şekil 1' de son 30 yıl içerisinde Web of Science (WOS) kapsamında yayınlanan pan-keskinleştirme konulu yayınların sayıs1 gösterilmektedir (Not: Şekilde gösterilen say1lar WOS arayüzünde (https://www.webofscience.com/wos/woscc/basicsearch) pan-keskinleştirme konulu yayınların taranması ile elde edilmiştir).

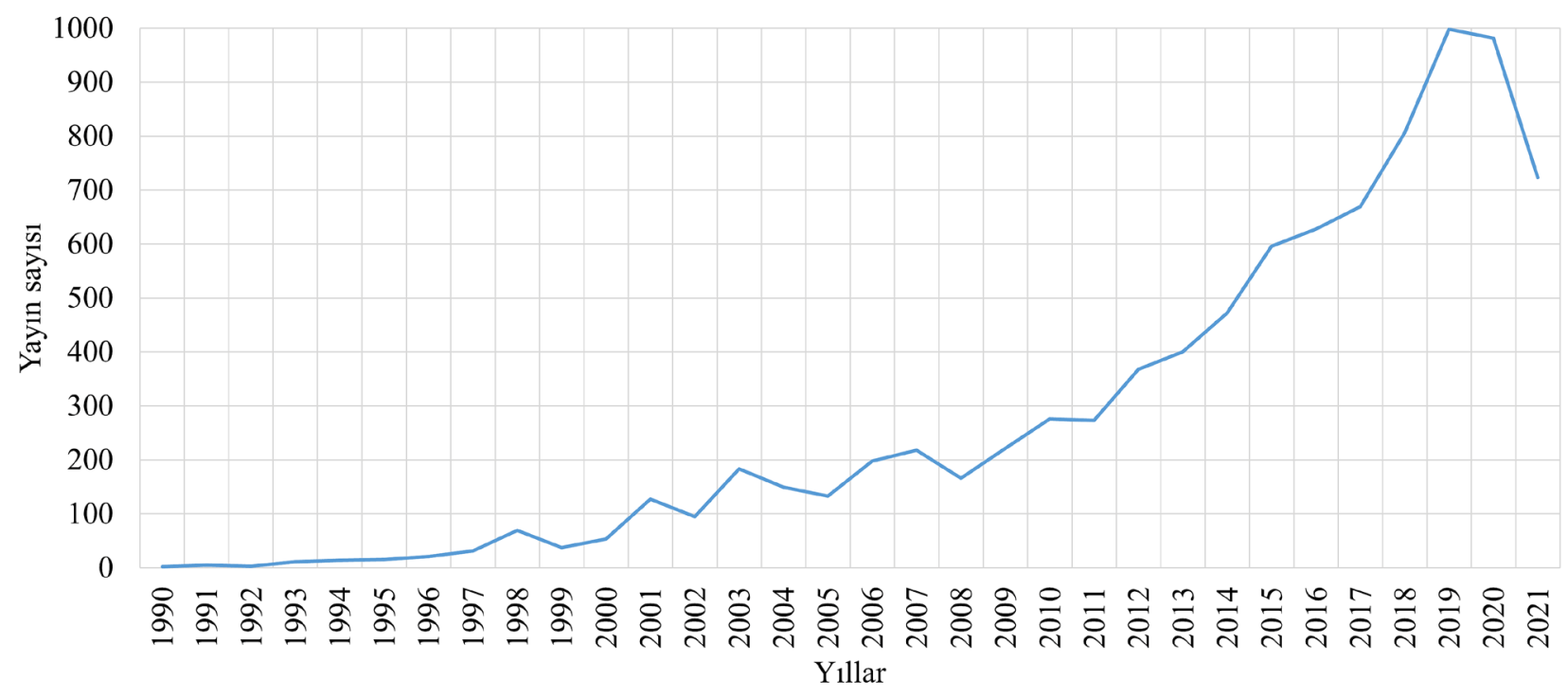

Şekil 1. Son 30 yıl içinde WOS kapsamında yayınlanan pan-keskinleştirme konulu yayın sayıları. 
Pan-keskinleştirme literatürü incelendiğinde uzamsal detay içeriğini korurken aynı zamanda spektral kaliteyi de tam anlamıyla koruyan bir pankeskinleştirme yönteminin şu ana kadar geliştirilemediği görülmektedir (Pohl ve van Genderen, 2016; Serifoglu Yilmaz vd., 2020). Bu durum araştırmacıları geliştirdikleri yeni yaklaşımlar ile bu problemi çözme veya tam anlamıyla bir çözüm sağlanamasa bile spektral ve uzamsal detay kalitesi arasında daha başarılı bir dengeye ulaşabilme noktasında teşvik etmektedir (Yilmaz vd., 2021). Bu nedenle, pankeskinleştirme literatürü farklı pan-keskinleştirme yaklaşımları ile günden güne büyümektedir (Bkz. Şekil 1). Bunun negatif bir getirisi olarak, kendi uygulamaları için pan-keskinleştirmeye ihtiyaç duyan kullanıcılar hangi yöntemin kullanılması gerektiği konusunda tereddüte düşmektedir. Pankeskinleştirmedeki bir diğer önemli husus ise pankeskinleştirme ile üretilen görüntülerin spektral ve uzamsal detay kalitelerinin irdelenmesidir. Pankeskinleştirilmiş görüntülerin kaliteleri görsel (nitel) olarak irdelenebildiği gibi, geliştirilen bazı kalite metrikleri yardımıyla sayısal (nicel) olarak da irdelenebilmektedir (Serifoglu Yilmaz vd., 2019). Nicel değerlendirme amaciyla geliştirilen oldukça fazla sayıda kalite metriği bulunmaktadır. $\mathrm{Bu}$ metriklerin her biri spektral veya uzamsal detay kalitesini farklı yaklaşımlar ile ölçmektedir, dolayisıyla, her birinin kendine has avantaj ve dezavantajları bulunmaktadır.
Güncel literatür incelendiğinde pan-keskinleştirme gibi önemli bir konudaki Türkçe kaynak eksikliği göze çarpmaktadır. Bu nedenle, bu çalışmanın amacı pan-keskinleştirme konsepti hakkında temel bilgiler sağlamak, şu ana kadar geliştirilen konvansiyonel ve modern pan-keskinleştirme stratejileri hakkında detaylı bir inceleme sunmak, üretilen pan-keskinleştirilmiş görüntülerin spektral ve uzamsal detay kalitelerinin nasıl irdelenebileceği hususunda bilgiler vermek ve son olarak hangi durumlarda hangi pan-keskinleştirme stratejilerinin kullanılabileceği hakkında ipuçları vermektir.

\section{Pan-keskinleștirme}

Pan-keskinleştirmede amaç, uzamsal detay kalitesi (uzamsal çözünürlüğü) yüksek olan bir pankromatik görüntünün içerdiği detayların uzamsal çözünürlüğü daha düşük olan çok bantlı bir görüntüye aktarılarak hem uzamsal detay kalitesi hem de spektral çözünürlüğü yüksek çok bantlı bir görüntü üretmektir. Pan-keskinleştirme işlemi sonucunda elde edilen görüntünün uzamsal çözünürlüğünün, girdi pankromatik görüntünün uzamsal çözünürlüğüne sahip olması beklenmektedir. Uygulama sonucunda uzamsal detay içeriği arttırılırken girdi çok bantlı görüntünün spektral içeriği de korunuyorsa pankeskinleştirme işleminin başarıyla gerçekleştirildiği söylenebilir (Yilmaz vd., 2021). Pan-keskinleştirme konsepti Şekil 2' de gösterilmiştir.
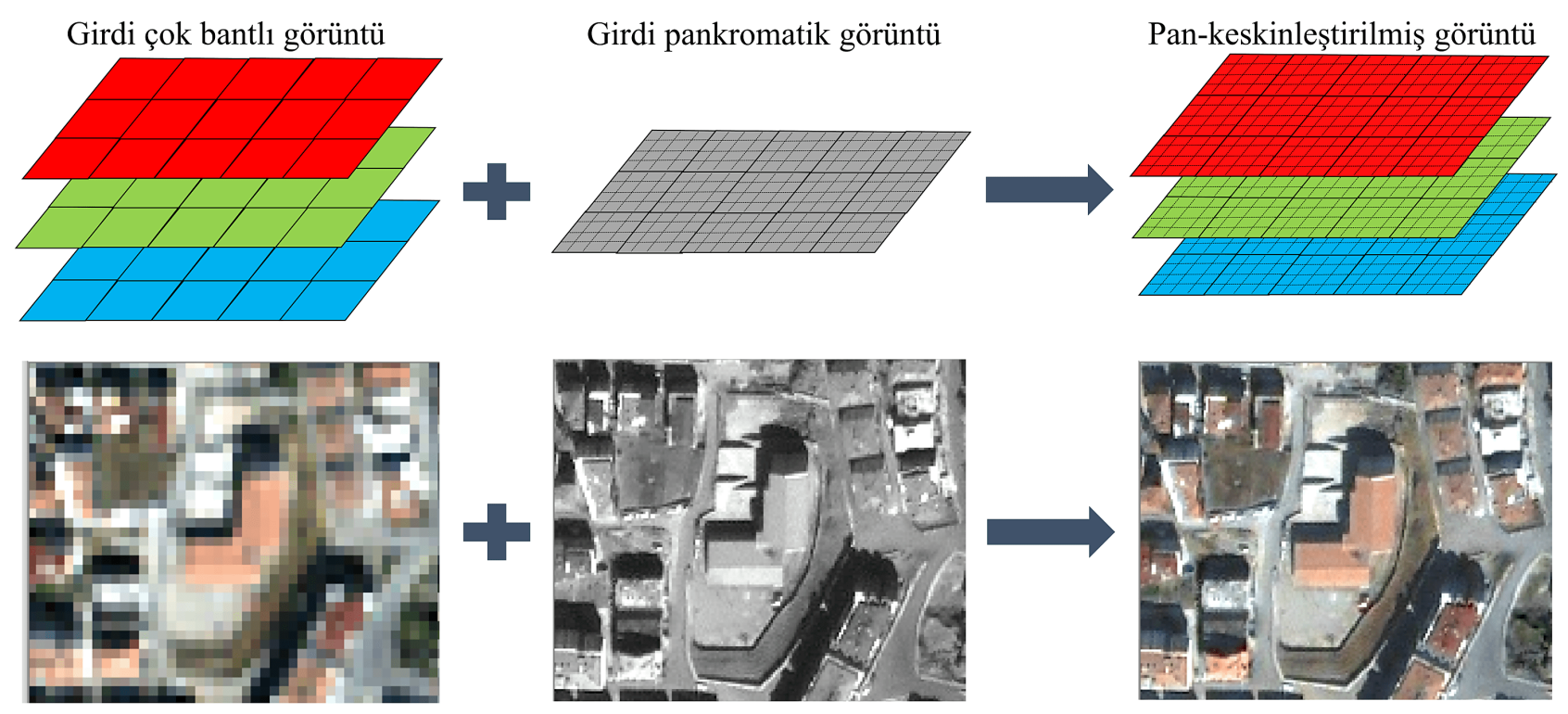

Şekil 2. Pan-keskinleştirme konsepti (Serifoglu Yilmaz, 2020).

Pan-keskinleştirme işleminin başarısına etki eden çeşitli faktörler vardır (Serifoglu Yilmaz vd., 2020; Yilmaz vd., 2021). Uygulamada kullanılacak olan pankromatik ve çok bantlı görüntülerin uzamsal çözünürlükleri arasında ne kadar fazla fark varsa pan-keskinleştirme işlemi o kadar zor olmaktadır 
(Yilmaz ve Gungor, 2016b; Serifoglu Yilmaz vd., 2020). Ayrıca girdi görüntülerin aynı sensör tarafindan üretilip üretilmediği de pankeskinleştirme işleminin başarısına doğrudan etki etmektedir. Faklı sensörlerden elde edilen görüntüler elektromanyetik spektrumun farklı aralıklarına duyarlı olduklarından dolayı bu görüntüler ile pan-keskinleştirme yapıldığında renk bozulmaları kaçınılmaz olacaktır (Serifoglu Yilmaz vd., 2020). Pan-keskinleştirme işleminin başarısına etki eden bir diğer etmen ise girdi çok bantlı ve pankromatik görüntülerin projeksiyon bilgileridir. Eğer girdi görüntüler farklı projeksiyon bilgilerine sahipse bir başka deyişle farklı koordinat sistemlerinde tanımlıysa bu görüntülerin pan-keskinleştirilmesi sonucunda elde edilen görüntüdeki uzamsal detaylarda kayıklıklar olacaktır. Diğer bir yandan, yüksek pankeskinleştirme başarısı için girdi görüntülerin çekim tarihleri birbirine yakın olmalıdır. Eğer girdi görüntülerin çekim tarihleri arasında fazla fark varsa bir görüntüdeki uzamsal detaylar diğer görüntüde olmayacağından dolayı pankeskinleştirilmiş görüntüde yapay renkler oluşacak (Pohl ve van Genderen, 1998) ve dolayısıyla renk bozulmaları kaçınılmaz olacaktır. Ayrıca pankeskinleştirmede kullanılacak olan görüntülerde çeşitli atmosferik veya radyometrik bozulmalar mevcutsa bu bozuklukların uygulamadan önce giderilmesi pan-keskinleştirme performansına olumlu etki yapacaktır. Pan-keskinleştirme başarısına etki eden bir diğer faktör ise kullanıcının tecrübesidir. Eğer kullanıcı yöntemlerin çalışma prensipleri ve zayıf yönleri hakkında bilgi sahibiyse hangi durumlarda hangi yöntemi kullanması gerektiğini kestirebilir ve bu sayede de maksimum pan-keskinleştirme performansına ulaşabilir (Serifoglu Yilmaz vd., 2020).

\section{Pan-keskinleştirme yöntemleri}

1980’ lerden günümüze kadar literatürde oldukça fazla sayıda pan-keskinleştirme yöntemi tanımlanmıştır. $\mathrm{Bu}$ yöntemler incelendiğinde bunların ya spektral yapıyı ya da uzamsal detay içeriğini koruma eğiliminde oldukları görülmektedir. Dolayısıyla 'en iyi pankeskinleştirme yöntemi' diye bir şeyden söz etmek mümkün değildir (Pohl ve van Genderen, 2016; Serifoglu Yilmaz vd., 2020; Yilmaz vd., 2020). Bu nedenle pan-keskinleştirme uygulamayı düşünen araştırmacilar ya spektral ya da uzamsal detay kalitesinden belli oranda feragat etmek zorunda olduklarını göz önünde bulundurmalıdır.

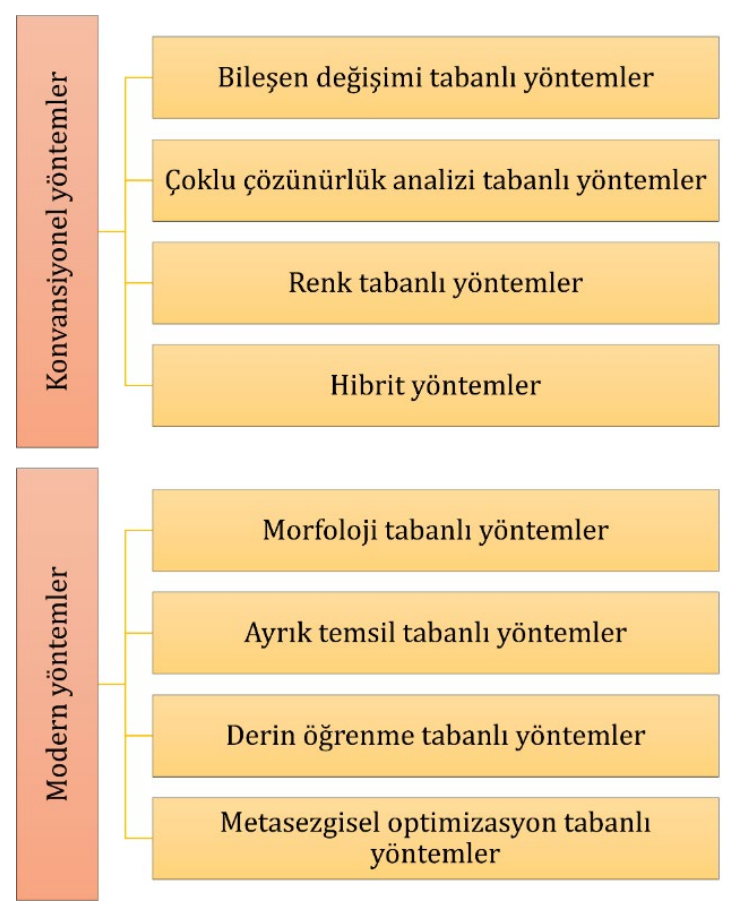

Şekil 3. Pan-keskinleştirme yöntemlerinin siniflandırılması

Güncel literatür incelendiğinde pan-keskinleştirme yöntemlerinin sinıflandırılmasina dair bir standardın olmadığı görülmektedir. Sınıflandırma için farkl1 kriterler göz önünde bulundurulduğundan aynı pan-keskinleştirme yönteminin farklı çalışmalarda farklı kategoriler altında gösterilmesi sıklıkla karşılaşılan bir durumdur. Örneğin, Yumuşatma Filtresi Tabanlı Yoğunluk Modülasyonu (Smoothing Filter-Based Intensity Modulation - SFIM) yöntemi (Liu, 2000) Vivone vd., (2015) tarafından çoklu çözünürlük analizi (multiresolution analysis) tabanlı yöntemler kategorisinde değerlendirilirken Yilmaz vd., (2020) tarafindan renk tabanlı yöntemler kategorisinde değerlendirilmiştir. $\mathrm{Bu}$ çalışmada pan-keskinleştirme yöntemleri konvansiyonel ve modern yöntemler olmak üzere iki başlık altında incelenmiştir. Literatürde yer alan konvansiyonel pan-keskinleştirme yöntemleri; bileşen değişimi (component substitution) tabanl, çoklu çözünürlük analizi tabanlı, renk tabanlı ve hibrit yöntemler olmak üzere dört kategori altında incelenmiştir. Modern yöntemler başlığı altında ise morfoloji tabanl1, ayrık temsil (sparse representation) tabanl, derin öğrenme (deep learning) tabanlı ve metasezgisel optimizasyon (metaheuristic optimization) tabanlı yöntemlere yer verilmiştir (Bkz. Şekil 3). 


\subsection{Konvansiyonel yöntemler}

\subsubsection{Bileşen değişimi tabanlı yöntemler}

Bileşen değişimi tabanlı yöntemler, girdi çok bantlı görüntüyü spektral ve uzamsal detayların farklı bileşenlerde depolanabildiği farklı bir uzaya dönüştürür. $\mathrm{Bu}$ yeni uzayda, uzamsal detayları barındıran bileşen girdi pankromatik görüntü ile yer değiştirir. Elde edilen veriye ters dönüşüm uygulanarak orijinal uzayda pan-keskinleştirilmiş görüntü üretilmiş olur (Ghassemian, 2016). Bileşen değişimi tabanlı yöntemler genellikle yüksek uzamsal detay kalitesinde görüntüler vaat etmelerine rağmen girdi çok bantlı görüntünün renk yapısını bozma eğilimindedir (Xing vd., 2018; Serifoglu Yilmaz vd., 2020). Ayrıca kullanımları kolaydır ve karmaşık matematiksel hesaplamalara dayanmazlar (Ghahremani vd., 2019; Serifoglu Yilmaz vd., 2019). Çarpımsal (Multiplicative) yöntem (Crippen, 1989), Brovey yöntemi (Hallada ve Cox, 1983), Sentetik Değişken Oranı (Synthetic Variable Ratio - SVR) yöntemi (Munechika vd., 1993), Intensity-Hue-Saturation (IHS) yöntemi (Haydn vd., 1982), Modifiye edilmiş IHS (MIHS) yöntemi (Siddiqui, 2003), Temel Bileşenler Analizi (Principal Component Analysis - PCA) yöntemi (Chavez ve Kwarteng, 1989), GramSchmidt (GS) yöntemi (Laben ve Brower, 2000), Adaptif GS (AGS) yöntemi (Aiazzi vd., 2007) ve Ehlers yöntemi (Ehlers, 2004; Klonus ve Ehlers, 2007) sıklıkla kullanılan bileşen değişimi tabanlı yöntemlerdendir.

En basit pan-keskinleştirme yöntemlerinden biri olan çarpımsal yöntem, girdi çok bantlı görüntünün her bir bandını girdi pankromatik görüntü ile çarparak pan-keskinleştirilmiş görüntünün her bir bandını oluşturur (Crippen, 1989). Bu çarpım işlemi piksel vektörlerini gereğinden fazla büyüttüğü için bu yöntem renk kalitesine yüksek oranda zarar vermektedir (Yilmaz vd., 2020). Çarpımsal yöntemin gelişmiş bir hali olan Brovey yöntemi, öncelikle girdi çok bantlı görüntünün her bir bandını girdi pankromatik görüntü ile çarpar, sonrasında bu görüntüyü girdi çok bantlı görüntünün bantlarının toplanmasıyla elde edilen bir yoğunluk görüntüsüne bölerek pankeskinleştirilmiş bantları oluşturur (Hallada ve Cox, 1983). Brovey yöntemi yoğunluk görüntüsünü üretirken girdi çok bantlı görüntünün bantlarının ağırlıklarını eşit kabul eder. Ancak, teorik olarak birçok senaryoda her bir bandın pankeskinleştirmeye katkısı eşit olamaz. Dolayısıyla renk kalitesini daha başarılı bir şekilde korumak için her bir banda gerçekçi bir ağırlık atanmalıdır (Serifoglu Yilmaz vd., 2020). SVR yöntemi
Brovey yönteminin geliştirilmiş halidir. Brovey yönteminde yoğunluk görüntüsü girdi çok bantlı görüntünün bantlarının toplamıyla elde edilirken SVR yönteminde bu görüntü girdi çok bantlı görüntünün bantlarının ağırlıklı toplamı şeklinde elde edilmektedir. Bant ağırlıkları ise regresyon analizi ile belirlenmektedir (Munechika vd., 1993). $\mathrm{Bu}$ yaklaşım çarpımsal yöntem ve Brovey yöntemine oranla daha başarılı renk korunumu sunmaktadır (Serifoglu Yilmaz vd., 2019).

Diğer bir bileşen değişimi tabanlı yöntem olan IHS yöntemi, girdi çok bantl görüntüye IHS dönüşümü uygulayarak görüntüyü IHS uzayına dönüştürür. Elde edilen yoğunluk (intensity) bileşeni ile girdi pankromatik görüntü yer değiştirir ve ters IHS dönüşümü ile pan-keskinleştirilmiş görüntü elde edilir (Haydn vd., 1982). IHS yönteminin en büyük dezavantajı sadece üç banda sahip olan çok bantlı görüntüler ile çalışabilmesidir. $\mathrm{Bu}$ nedenle bant sayısı üçten fazla olan görüntüler için MIHS yöntemi geliştirilmiştir. MIHS yöntemi pankeskinleştirilmiş görüntüyü girdi çok bantlı görüntünün üçlü bant kombinasyonları şeklinde hesaplamaktadır (Siddiqui, 2003). MIHS yönteminin performansı girdi görüntülerin duyarlı oldukları elektromanyetik spektrum aralığına bağlıdır. Eğer girdi görüntüler aynı sensörden elde edilmişse MIHS yöntemi daha yüksek performans sergileme eğilimindedir. MIHS yönteminin performansını etkileyen bir diğer faktör ise kullanılan IHS dönüşümüdür. Farklı IHS dönüşümleri ile farklı kalitelerde pankeskinleştirilmiş görüntüler elde etmek mümkündür (Serifoglu Yilmaz vd., 2019).

Literatürde sıklıkla kullanılan bileşen değişimi tabanlı yöntemlerden biri olan PCA yöntemi, ilk aşama olarak girdi çok bantlı görüntüye temel bileşenler analizi dönüşümü uygular. Elde edilen ilk temel bileşenin görüntüdeki varyans (uzamsal detay) bilgisinin tamamını içerdiği varsayımına dayanarak girdi pankromatik görüntüyü bu bileşenin yerine koyar. Son aşama olarak ters PCA dönüşümü ile pan-keskinleştirilmiş görüntü üretilir (Chavez ve Kwarteng, 1989). GS yöntemi, PCA yöntemine oldukça benzeyen başka bir istatistik tabanlı yöntemdir. Çalışma prensibi PCA' ya oldukça yakın olan GS yöntemi ilk aşama olarak girdi çok bantlı görüntünün bantlarını kullanarak düşük çözünürlüklü bir pankromatik görüntü üretir. Standart GS yöntemi bu pankromatik görüntüyü girdi çok bantlı görüntünün bantlarının ortalaması şeklinde hesaplamaktadır. Kullanıcı tarafindan başka bir düşük çözünürlüklü pankromatik görüntü tanımlamak da mümkün olmakla beraber bu pankromatik görüntü, girdi pankromatik 
görüntünün alçak geçirgen (low-pass) bir filtre ile filtrelenmesi ile de elde edilebilir (Yilmaz, 2021). Elde edilen düşük çözünürlüklü pankromatik görüntü ve girdi çok bantlı görüntünün bantları vektöre dönüştürülür. Çok bantlı görüntünün bantlarına ait vektörler ve düşük çözünürlüklü görüntü vektörü birleştirildikten sonra GS dönüşümü uygulanır. Burada ilk bileşen vektörü ile girdi pankromatik görüntü vektörü yer değiştirilir. Son aşama olarak elde edilen veriye ters GS dönüşümü uygulanarak pan-keskinleştirilmiş görüntü üretilir (Laben ve Brower, 2000). GS yönteminin gelişmiş bir versiyonu olan AGS yöntemi, düşük çözünürlüklü pankromatik görüntüyü girdi çok bantlı görüntünün bantlarının ağırlıklı ortalaması şeklinde hesaplar. Bantların ağırlıkları, girdi pankromatik görüntü ve çok bantlı görüntünün bantlarının çok değişkenli regresyonuyla kestirilir (Aiazzi vd., 2007). PCA ve GS tabanlı pan-keskinleştirme yöntemleri istatistiksel temellere dayanır ve performansları büyük oranda çalışma bölgesinin karakteristiklerine ve girdi görüntüler arasındaki istatistiksel ilişkiye bağlıdır (Yilmaz vd., 2021).

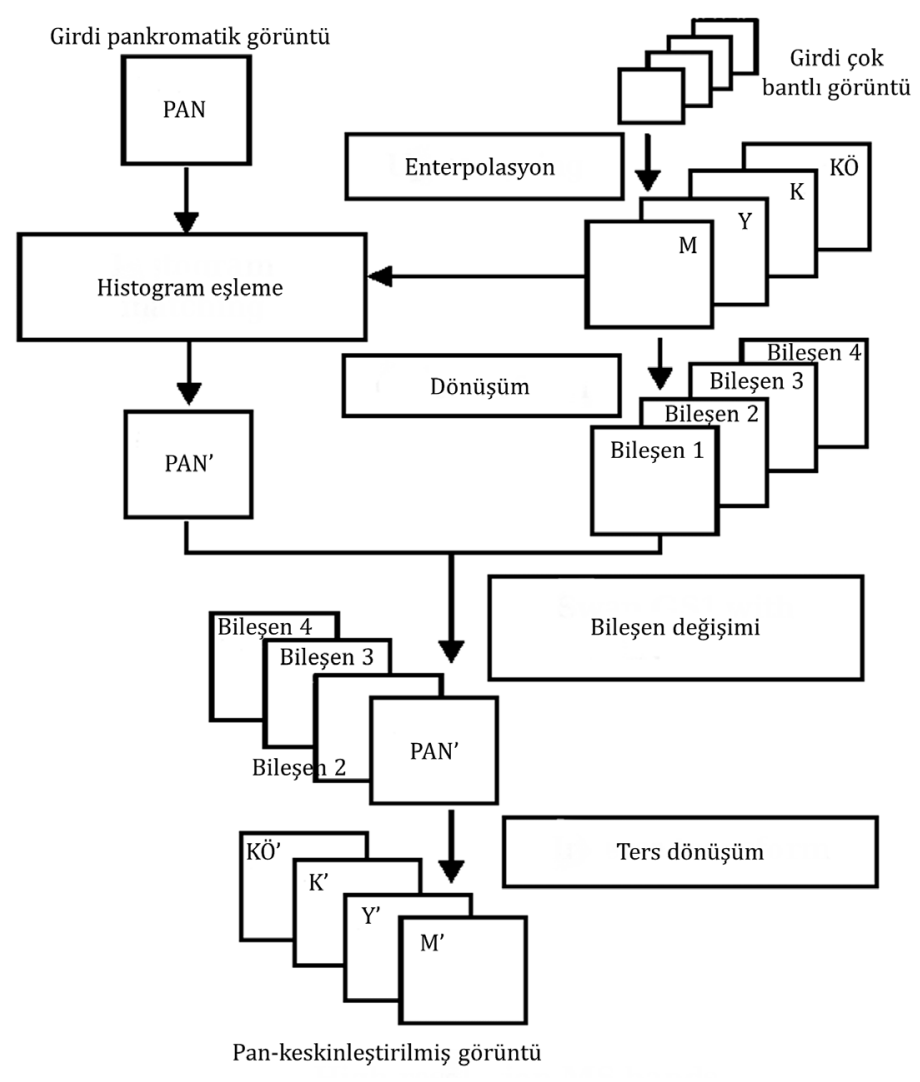

Şekil 4. Bileşen değişimi tabanlı pan-keskinleştirme yöntemlerinin çalışma prensibi (Hallabia vd., 2014) (M, Y, K, KÖ, sırasıyla mavi, yeşil, kırmızı ve kızıl ötesi bantları temsil etmektedir).

$\mathrm{Bu}$ kategoride incelenecek diğer bir pankeskinleştirme algoritması olan Ehlers yönteminde, ilk aşama olarak girdi çok bantlı görüntüye IHS dönüşümü uygulanır. Ardından IHS dönüşümü ile elde edilen yoğunluk bileşeni ve girdi pankromatik görüntü Fourier uzayına dönüştürülür. $\mathrm{Bu}$ uzayda, pankromatik spektrum bir yüksek geçirgen filtre ile, yoğunluk spektrumu ise düşük geçirgen bir filtre ile filtrelenir. Filtrelenen spektrumlar ters Fourier dönüşümü ile orijinal renk uzayına geri döndürülür ve bu uzayda elde edilen görüntüler toplanarak yeni yoğunluk bileşeni üretilir. $\mathrm{Bu}$ yeni yoğunluk bileşeni daha önceden elde edilen renk (hue) ve beyaza doygunluk (saturation) bileşenleri ile birlikte ters
IHS dönüşümüne tabi tutularak pankeskinleştirilmiş görüntü üretilir (Ehlers, 2004; Klonus ve Ehlers, 2007). Ehlers yöntemi girdi görüntüleri frekans uzayında filtrelediği için spektral ve uzamsal detay bilgisini yüksek oranda koruma eğilimindedir. Ayrıca yöntem, IHS dönüşümünden faydalandığı için performans1 kullanılan IHS dönüşümüne bağlıdır. Ehlers yönteminin en büyük avantajlarından biri ise kullanıcılara frekans uzayında kullanacakları filtrelerin türlerini ve boyutlarını belirleme imkânı sunmasıdır. Bu sayede kullanıcılar arzu ettikleri kalitede spektral ve uzamsal detay kalitesine ulaşabilmektedirler (Serifoglu Yilmaz vd., 2020). Şekil 4 bileşen değişimi tabanlı pan-keskinleştirme 
yöntemlerinin çalışma prensibini genel olarak özetlemektedir.

\subsection{2. Çoklu çözünürlük analizi tabanl yöntemler}

Çoklu çözünürlük analizi tabanlı yöntemler literatürde siklıkla kullanılan yöntemler arasındadır. Bu yöntemler genel olarak üç aşamada uygulanır (Ghassemien, 2016). İlk aşamada, girdi görüntüler dalgacık (wavelet) dönüşümü veya piramit dönüşümü gibi çoklu çözünürlük ayrıştırma (decomposition) algoritmaları ile belli sayıda ölçek seviyesinde ayrıştırılır. İkinci aşamada, spektral ve uzamsal detaylar belli kaynaştırma (fusion) kurallarına göre kaynaştırılır. Son aşamada ise ters çoklu çözünürlük ayrıştırma dönüşümü ile pan-keskinleştirilmiş görüntü orijinal renk uzayında üretilir. Bileşen değişimi tabanlı yöntemlerin aksine, çoklu çözünürlük analizi tabanlı yöntemler yüksek renk kalitesi vaat ederken girdi pankromatik görüntünün uzamsal detay içeriğini koruyamamaktadır (Yang vd., 2018; Serifoglu Yilmaz vd., 2019). Ayrik Dalgacik Dönüşümü (Discrete Wavelet Transformation DWT) yöntemi (El-Samie vd., 2012), Eklemeli à trous Dalgacık Dönüşümü (Additive à trous Wavelet Transformation - ATWT) yöntemi (Núñez vd., 1999; Garzelli ve Nencini, 2006), Additive Wavelet Luminance Proportional (AWLP) yöntemi (Otazu vd., 2005), Indusion yöntemi (Khan vd., 2008), Modülasyon Transfer Fonksiyonu (MTF) Tabanlı Genelleştirilmiş Laplacian Piramidi (MTF-GLP) yöntemi (Aiazzi vd., 2006) ve Yüksek Geçirgen Modülasyon (HighPass Modulation - HPM) Tabanl1 MTF-GLP (MTF-GLP-HPM) yöntemi (Vivone vd., 2014) en popüler çoklu çözünürlük analizi tabanlı pankeskinleştirme yöntemlerindendir.

DWT yöntemi, öncelikle girdi pankromatik görüntüye ardı ardına dalgacık dönüşümü uygular. Her bir dalgacık dönüşümünde uzamsal çözünürlüğü iki kat kötüleşmiş orijinal görüntünün yarısı boyutlarında dört adet dalgacık bileşeni üretilmektedir. $\mathrm{Bu}$ bileşenlerden biri renk detaylarını barındırırken diğerleri yatay, düşey ve çapraz yönlerdeki uzamsal detay içeriğini barındırır. Toplamda kaç seviye dalgacık dönüşümü uygulanacağ1 girdi görüntülerin uzamsal çözünürlüklerinin oranına bağlıdır. Pankromatik görüntüden elde edilen dalgacık bileşenlerinin uzamsal çözünürlügüü girdi çok bantl1 görüntünün bantlarının uzamsal çözünürlüğüne ulaşana kadar dalgacık dönüşümlerine devam edilir. Dalgacık dönüşümleri tamamlandığında, yani en son seviye dalgacık bileşenleri elde edildiğinde, girdi çok bantlı görüntünün her bir bandı pankromatik görüntüden edilen renk bileşeni ile yer değiştirir ve ters dalgacık dönüşümü uygulanarak her bir pan-keskinleştirilmiş bant elde edilmiş olur (El-Samie vd., 2012). DWT yöntemi her bir dalgacık dönüşümünü elde edilen renk bileşenine uyguladığından dolayı arka arkaya uygulanan dalgacık dönüşümleri uzamsal detay kaybına yol açmaktadır (Yilmaz vd., 2021). Ayrıca yöntem ağırlıklı olarak yatay, düşey ve çapraz yöndeki uzamsal detayları çıkartmaktadır. Bu nedenle diğer yönlerde uzanan uzamsal detayların yutulması söz konusudur.

ATWT yönteminde, girdi pankromatik görüntüye ardı ardına à trous dalgacık dönüşümü uygulanır. Yatay, düşey ve çapraz yöndeki uzamsal detayları barındıran dalgacık dönüşümü katsayıları girdi çok bantlı görüntünün her bir bandına eklenerek pankeskinleştirilmiş bantlar üretilir (Núñez vd., 1999; Garzelli ve Nencini, 2006). ATWT yöntemi de DWT yöntemi gibi yatay, düşey ve çapraz yöndeki uzamsal detayları çıkartmaktadır. Dolayısıyla diğer yönlerde uzanan uzamsal detaylarda bozulmalar meydana gelmektedir. ATWT yönteminin en büyük avantaj1, her bir seviye dalgacık dönüşümünde ayrıştırma penceresinin boyutunu ayrıştırma katsayılarının arasına 0' lar ilave ederek arttırmasıdır. Bu sayede varyans kayması (shiftvariance) problemi çözülmüş olup daha etkin renk bileşenleri üretilebilmektedir (Serifoglu Yilmaz vd., 2019). ATWT yönteminde her bir ayrıştırma sonras1 görüntünün boyutları aynı kalmaktadır. Diğer bir çoklu çözünürlük tabanlı yöntem olan AWLP yöntemi, à trous dalgac1k dönüşümü ile elde ettiği uzamsal detay bilgisini belli bir oran dahilinde girdi çok bantlı görüntünün bantlarına enjekte eder (Otazu vd., 2005). Bu yöntem girdi pankromatik görüntünün histogramını IHS dönüşümüyle elde edilen yoğunluk bileşeninin histogramına eşler. $\mathrm{Bu}$ eşleme esnasında uzamsal detayların belli oranda kaybolduğu gözlemlenir. Ancak diğer yandan, uzamsal detayların belli bir oran dâhilinde enjekte edilmesi bantlar arasındaki istatistiksel ilişkinin pan-keskinleştirme sonrasında da korunmasını sağlamaktadır (Serifoglu Yilmaz vd., 2019). Aynı kategoride incelenen indusion yöntemi, yukarı yönlü ölçekleme (upscaling) işlemini daha etkin bir şekilde gerçekleştiren 'induction' yaklaşımından faydalanmaktadır. Indusion yöntemi yukarı yönlü ölçekleme ve aşağı yönlü ölçekleme (downscaling) filtreleri ile pankromatik görüntüden çıkartılan uzamsal detayları yukarı yönde ölçeklenmiş girdi çok bantlı görüntüye enjekte etmektedir (Khan vd., 2008).

MTF-GLP yöntemi, girdi çok bantlı görüntüyü üreten sensöre ait olan MTF' yi kullanarak bir 
indirgeme filtresi üretir. Sonra, girdi çok bantlı görüntünün spektral özelliklerinin korunmasına olanak sağlayan bir kısıtlamayı dikkate alarak uzamsal detay bilgisini seçici olarak girdi çok bantlı görüntünün bantlarına enjekte eder (Aiazzi vd., 2006). MTF-GLP yöntemi, MTF filtresi aracılığıyla indirgenen pankromatik görüntüyü girdi pankromatik görüntüden çıkartarak uzamsal bilgileri elde eder. $\mathrm{Bu}$ yaklaşım düşük renk frekansına sahip alanlarda renk özelliklerinin korunmasını sağlamaktadır (Yilmaz, 2021). MTFGLP-HPM yöntemi, aşağı yönlü ölçeklemeden önce MTF' den faydalanır ve bir yandan girdi çok bantlı görüntünün spektral özelliklerini korurken diğer yandan, uzamsal ayrıntıları enjekte etmek için uzamsal özelliklerin çarpımına dayanan bir HPM enjeksiyon yaklaşımı kullanır (Xing vd., 2018; Yilmaz, 2021). Bu enjeksiyon yaklaşımının uzamsal detay içeriğini belli oranda koruduğu gözlemlenmiştir (Yilmaz, 2021). Şekil 5 dalgacık dönüşümü tabanlı pan-keskinleştirme yöntemlerinin çalışma prensibini genel olarak özetlemektedir.

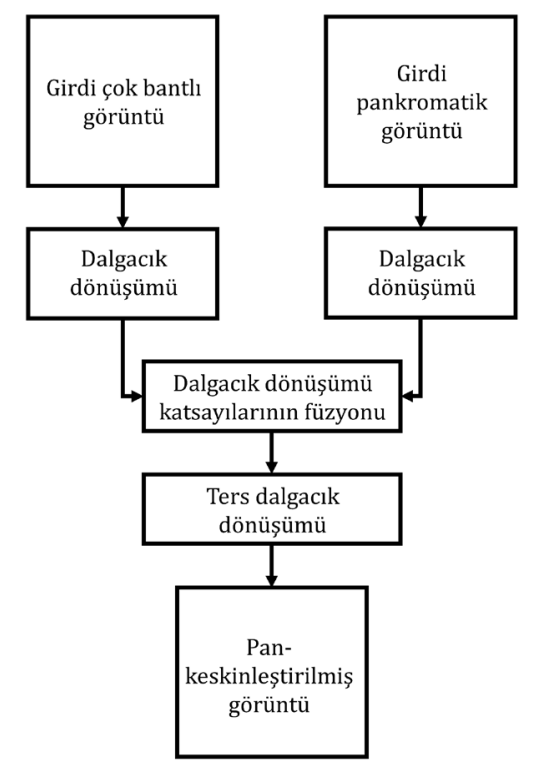

Şekil 5. Çoklu çözünürlük analizi tabanlı pan-keskinleştirme yöntemlerinin çalışma prensibi (Jinju vd., 2019).

\subsubsection{Renk tabanll yöntemler}

Renk tabanlı pan-keskinleştirme yöntemleri, adı üstünde, öncelikli olarak renk yapısını korumak için farklı prosedürlerden faydalanan yöntemlerdir. Lokal Ortalama Eşleme (Local Mean Matching LMM) yöntemi (de Béthune vd., 1997), Lokal Ortalama Varyans Eşleme (Local Mean Variance Matching - LMVM) yöntemi (de Béthune vd., 1997), SFIM yöntemi (Liu, 2000), Yüksek Geçirgen Filtreleme (High-Pass Filtering - HPF) yöntemi (Schowengerdt, 1980) ve Kriter Tabanlı yöntem (Gungor, 2008) en popüler renk tabanlı pan-keskinleştirme algoritmalarından bazılarıdır.

LMM yöntemi, girdi görüntülerin bant ortalamalarını pan-keskinleştirilmiş görüntünün bant ortalamasına eşlemek için lokal pencerelerden faydalanır (de Béthune vd., 1997). LMVM yöntemi ise LMM yöntemine benzer şekilde, lokal pencereler aracılı̆̆ıla girdi görüntülerin bantlarının ortalama ve varyans değerlerini pankeskinleştirilmiş görüntünün bantlarının ortalama ve varyans değerlerine eşlemektedir (de Béthune vd., 1997). LMM ve LMVM yöntemlerinin performansı kullanılan lokal pencerenin boyutuyla doğrudan ilişkilidir. En başarılı pan-keskinleştirme sonucu için en uygun lokal pencere boyutunu belirlemek kullanıcılar açısından bir zorluk teşkil etmektedir.

SFIM yöntemi, girdi çok bantlı görüntünün her bir bandını girdi pankromatik görüntü ile çarpar. Elde edilen görüntü, alçak geçirgen bir filtre ile filtrelenmiş pankromatik görüntüye bölünerek pankeskinleştirilmiş görüntü üretilir (Liu, 2000). SFIM yöntemi, girdi pankromatik görüntü ve onun alçak geçirgen bir filtre ile filtrelenmiş versiyonu arasındaki oranı direkt olarak kullandığından, uygulanan alçak geçirgen filtrenin boyutu yöntemin performansı açısından önem arz etmektedir (Serifoglu Yilmaz vd., 2019).

Bir diğer renk tabanlı yöntem olan HPF yöntemi, girdi pankromatik görüntünün uzamsal detay yapısını bir yüksek geçirgen filtre yardımıyla iyileştirir ve iyileştirilen uzamsal detay bilgisi girdi çok bantlı görüntünün bantlarına aktarılarak pankeskinleştirilmiş görüntü oluşturulur (Schowengerdt, 1980). Kullanılan yüksek geçirgen filtrenin içeriği ve boyutu HPF yönteminin performansında önemli rol oynamaktadır. Filtre boyutu arttıça daha keskin görüntüler elde edilmekle beraber renk kalitesinde bozulmalar meydana gelmektedir. $\mathrm{Bu}$ yöntemin en büyük dezavantajı optimum yüksek geçirgen filtrenin belirlenmesinin oldukça zor olmasıdır. Optimum filtreyi bulmak için kullanıcılar çoğu zaman birçok farklı filtre denemek zorunda kalmaktadır (Serifoglu Yilmaz vd., 2019).

Kriter tabanlı yöntem, pan-keskinleştirilmiş görüntüleri girdi çok bantlı görüntü ve pankromatik görüntünün doğrusal bir kombinasyonu şeklinde hesaplamaktadır. Yöntemde, girdi çok bantlı görüntü ve pankromatik görüntünün pankeskinleştirmeye katkılarını temsil eden iki katsayıyı belirlemek için üç kriterden 
faydalanılmaktadır. Birinci kritere göre uzamsal detay içeriğinin başarılı bir şekilde aktarılabilmesi için girdi pankromatik görüntünün varyansı pankeskinleştirilmiş görüntünün varyansına eşit olmalıdır. İkinci kritere göre renk yapısının başarıyla korunabilmesi için pan-keskinleştirilmiş görüntünün her bir bandının ortalaması kendisine karşılık gelen girdi çok bantlı görüntünün bant ortalamasına eşit olmalıdır. Üçüncü kritere göre ise girdi çok bantlı görüntünün bantları arasındaki oran pan-keskinleştirilmiş görüntünün bantları arasındaki orana eşit olmalıdır. Girdi görüntüler üzerinde gezdirilen pencereler yardımıyla bu üç kriter sağlanmaktadır (Gungor, 2008). Kriter tabanlı yöntemin performans1 gezdirilen pencerelerin boyutu ile yakından ilgilidir (Serifoglu Yilmaz vd., 2019). Gungor (2008), girdi görüntülerin uzamsal çözünürlüklerinin oranından büyük olan en küçük tek sayının boyutunda pencereler kullanılarak bu yöntemden maksimum pan-keskinleştirme performansı elde etmenin mümkün olduğunu belirtmektedir. Pencere boyutu büyüdükçe uzamsal detay kalitesi daha yüksek ancak spektral kalitesi daha düşük görüntüler elde edilmektedir (Gungor, 2008).

\subsubsection{Hibrit yöntemler}

Hibrit yöntemler birden fazla pan-keskinleştirme yönteminin avantajlarını birleştirmeyi amaçlamaktadır (González-Audícana vd., 2004). IHS-DWT yöntemi (El-Samie vd., 2012) ve Dalgacık Dönüşümü Tabanlı PCA yöntemi (WPCA) (Yusuf vd., 2013) literatürde siklikla kullanılan iki hibrit tabanlı pan-keskinleştirme yöntemidir. IHS-DWT yöntemi ilk aşama olarak girdi çok bantlı görüntüye IHS dönüşümü uygular. Daha sonra girdi pankromatik görüntünün histogramı IHS dönüşümü ile elde edilen yoğunluk görüntüsünün histogramına eşlenir. Ardından yoğunluk görüntüsüne ve histogramı eşlenen pankromatik görüntüye dalgacık (DWT) dönüşümü uygulanır. Yoğunluk görüntüsünden elde edilen renk bileşeni ile histogramı eşlenmiş pankromatik görüntüden elde edilen renk bileşeninin ortalaması alınarak elde edilen görüntü, yoğunluk görüntüsünden elde edilen renk bileşeni ile yer değiştirir. Sonrasında ters dalgacık (DWT) dönüşümü uygulanılarak yeni bir yoğunluk bileşenine ulaş1lır. Elde edilen bu yeni bileşene uygulanan ters IHS dönüşümü ile pankeskinleştirilmiş görüntü üretilir. IHS-DWT yöntemi, renk yapısındaki bozulmalar pahasına, DWT yönteminin uzamsal detayları yeterince aktaramama problemine kısmen çözüm sunmaktadır (Serifoglu Yilmaz vd., 2020).
Diğer bir hibrit yöntem olan W-PCA yöntemi girdi çok bantlı görüntüye PCA dönüşümü uygulayarak bantlar arasındaki korelasyonu minimize eder. Daha sonra girdi pankromatik görüntünün histogramı PCA dönüşümü ile elde edilen birinci temel bileşenin histogramına eşlenir. Histogramı eşlenen pankromatik görüntüye ve birinci temel bileşene dalgacık dönüşümü uygulanır. Sonrasında ters dalgacık dönüşümü ile pankromatik görüntüdeki uzamsal detaylar birinci temel bileşene aktarılır. Son aşamada ters PCA dönüşümü uygulanarak pan-keskinleştirilmiş görüntü üretilir (González-Audícana vd., 2004). W-PCA yöntemi, PCA yönteminin rengi bozma problemini kısmen ortadan kaldırmaktadır. Hibrit yöntemlerin barındırdıkları pan-keskinleştirme yöntemlerinin avantajlarını her durumda koruyamadıkları görülmektedir (Serifoglu Yilmaz vd., 2020).

\subsection{Modern yöntemler}

\subsubsection{Morfoloji tabanl yöntemler}

Çoklu çözünürlük analizi tabanlı pankeskinleştirme yöntemleri genellikle dalgacık dönüşümü veya Gauss piramitsel ayrıştırma (Gaussian pyramids) gibi doğrusal analiz operatörlerini kullanır. Morfolojik filtreler gibi doğrusal olmayan operatörlerin kullanımı piramitsel ayrıştırma işlemi için iyi bir alternatif oluşturmaktadır. Ayrıca bazı morfolojik filtreler uzamsal detayları korumada doğrusal filtrelerden daha etkilidir ve çeşitli uygulamalarda üstün performans sağlarlar (Restaino vd., 2015). Bölütleme (segmentation) ve gürültü giderme (denoising) gibi işlemler için morfoloji tabanlı yöntemlerin avantajlarından siklıkla faydalanılmasına rağmen, az sayıda pankeskinleştirme yaklaşımı bu yöntemlerden yararlanmaktadır (Restaino vd., 2016). Güncel literatür incelendiğinde son y1llarda araştırmacıların optimum pan-keskinleştirme performansı elde edebilmek için morfolojik operatörlerden faydalandıkları görülmektedir (Addeso vd., 2012; Restaino vd., 2016; Shi, 2018; Pandit ve Bhiwani, 2020). Addeso vd., (2012) çalışmalarında stokastik bir optimizasyon sağlayan genetik algoritmadan faydalanarak morfolojik operatörleri optimize etmek suretiyle pankeskinleştirme yapmışlardır. Restaino vd., (2015) morfolojik gradyan tabanlı bir çoklu çözünürlük analizi yaklaşımı ile girdi pankromatik görüntüdeki uzamsal detayları çıkarıp girdi çok bantlı görüntünün bantlarına enjekte ederek pankeskinleştirilmiş görüntü üretmişlerdir. Restaino vd., (2016) tarafından geliştirilen pan- 
keskinleştirme yöntemi, iki yarım gradyan arasındaki farktan türetilen bir morfolojik operatörle uzamsal ayrıntıları çıkarır ve bu ayrıntıları girdi çok bantlı görüntüye entegre eder. Morfolojik operatörlerin pan-keskinleştirme amacıyla kullanımının pan-keskinleştirme performansına olumlu katk1 yaptığ1 gözlemlenmiştir (Restaino vd., 2016).

\subsubsection{Ayrık temsil tabanlı yöntemler}

Son yıllarda ayrik temsil tekniklerindeki gelişmeler, araştırmacıları bu algoritmaları pankeskinleştirme için kullanmaya teşvik etmiştir. Ayrık temsil tabanlı ilk pan-keskinleştirme yöntemi Li ve Yang (2011) tarafindan geliştirilmiştir. $\mathrm{Bu}$ çalışmada yazarlar, yüksek çözünürlüklü çok bantlı görüntü parçaları kullanarak yükssek çözünürlüklü çok bantlı görüntü için bir sözlük oluşturmuşlardır. Ancak her zaman yüksek çözünürlüklü çok bantlı görüntü elde etmek mümkün olamamaktadır. Bu problemin çözümü için bazı yaklaşımlar sözlük öğrenmesinde (dictionary learning) girdi pankromatik görüntüyü kullanarak gerçekleştirirken (Zhu ve Bamler, 2013) bazı yaklaşımlar ise Ortak Sözlük Öğrenmesi (Joint Dictionary Learning) (Jiang vd., 2012) gibi yöntemlere başvurmaktadır. Bazı ayrık temsil tabanlı yaklaşımlar, girdi çok bantlı görüntünün yüksek çözünürlüklü başka çok bantlı bir görüntünün çözünürlügünün kötüleştirilmiş bir versiyonu olduğunu ve girdi pankromatik görüntünün ise yüksek çözünürlüklü bir çok bantlı görüntünün doğrusal bir kombinasyonu olduğunu varsaydıklarından dolayı kisitlı bir pankeskinleştirme performans1 sergileyebilmektedirler (Yin, 2015). Ayrik temsil tabanlı pan-keskinleştirme yöntemleri genellikle konvansiyonel yöntemlere göre daha başarılı performans sergilemelerine rağmen dezavantajları da bulunmaktadır. $\mathrm{Bu}$ yöntemler uzamsal detayların kaybolmasına neden olmakla beraber performansları girdi çok bantlı görüntünün ve pankromatik görüntünün başarılı bir şekilde üst üste çakıştırılmasına bağlıdır (Fei vd., 2019).

\subsubsection{Derin öğrenme tabanlı yöntemler}

Günümüzde derin öğrenme tekniklerinin farklı uygulamalardaki başarıları bu tekniklerin pankeskinleştirme alanında kullanımını beraberinde getirmiştir. Derin öğrenme tabanlı pan- keskinleştirme yaklaşımları, derin sinir ağları aracılığıyla girdi görüntü parçalarının hiyerarşik özelliklerinden faydalanarak pan-keskinleştirme işlemini gerçekleştirir (Xing vd., 2018). Bu amaçla, derin öğrenme tekniklerinden faydalanan ilk yaklaşımlar pan-keskinleştirme problemini bir Süper Çözünürlük (Super Resolution) problemi olarak ele almış ve üç katmanlı basit bir Evrişimsel Sinir Ağ 1 (Convolutional Neural Network - CNN) mimarisi ile pan-keskinleştirme işlemini gerçekleştirmişlerdir (Masi vd., 2016). Masi vd., (2016) tarafindan geliştirilen derin öğrenme tabanlı pan-keskinleştirme yöntemi (Bkz. Şekil 6) ilk aşama olarak girdi çok bantlı görüntünün çözünürlüğünü girdi pankromatik görüntünün çözünürlüğüne çıkartır. Çözünürlüğü arttırılan bantlar girdi pankromatik görüntü ile birleştirilir. $\mathrm{Bu}$ birleştirilmiş görüntü evrişimsel sinir ağının girdi katmanını oluşturmaktadır. Ağ önceden belirlenen iterasyon sayısındaki eğitim süreci boyunca evrişim süzgecinin (filtre) ve kurulan modelin parametrelerini öğrenmeye çalışmaktadır. Ağın eğitimi Wald vd., (1997) tarafindan önerilen protokole göre gerçekleştirilir. Bu protokole göre pan-keskinleştirilmiş bir görüntünün çözünürlüğü girdi çok bantlı görüntünün çözünürlügüne kötüleştirildiğinde elde edilen görüntü, girdi çok bantlı görüntü ile aynı olmalıdır.

Son zamanlarda araştırmacılar basit mimariye sahip olan evrişimsel sinir ağlarının kısıtlı kapasitelerinden kaynaklanan pan-keskinleştirme hatalarını azaltmak için Çekişmeli Üretici Ağ (Generative Adversarial Networks - GAN) mimarisi (Ozcelik vd., 2020), Derin Sinir Ağ (Deep Neural Network) mimarisi (Zhang vd., 2020) ve Derin Kalıntı A $\breve{g}$ (Deep Residual Network) mimarisi (Benzenati vd., 2020) gibi mimarilerden faydalanmaktadırlar. Derin öğrenme tabanlı pan-keskinleştirme yöntemleri doğrusal olmayan modelleme (nonlinear modeling) kapasitelerinden dolayı birçok konvansiyonel yönteme göre yüksek performans göstermektedir (Jiang vd., 2020). Ancak bu yöntemlerin sonuçları kurulan model, kullanıcı tarafindan belirlenen hiper parametreler ve eğitim süresi gibi birçok değişkene oldukça bağlıdır. Ayrıca eğitim için fazla sayıda örnek görüntüye ihtiyaç duyulması bu yöntemlerin başlıca dezavantajlarındandır. Yüksek sistem özelliklerine ihtiyaç duyan bu yöntemler eğitim-test süreçlerinden dolayı genellikle yavaş çalışmaktadır. 


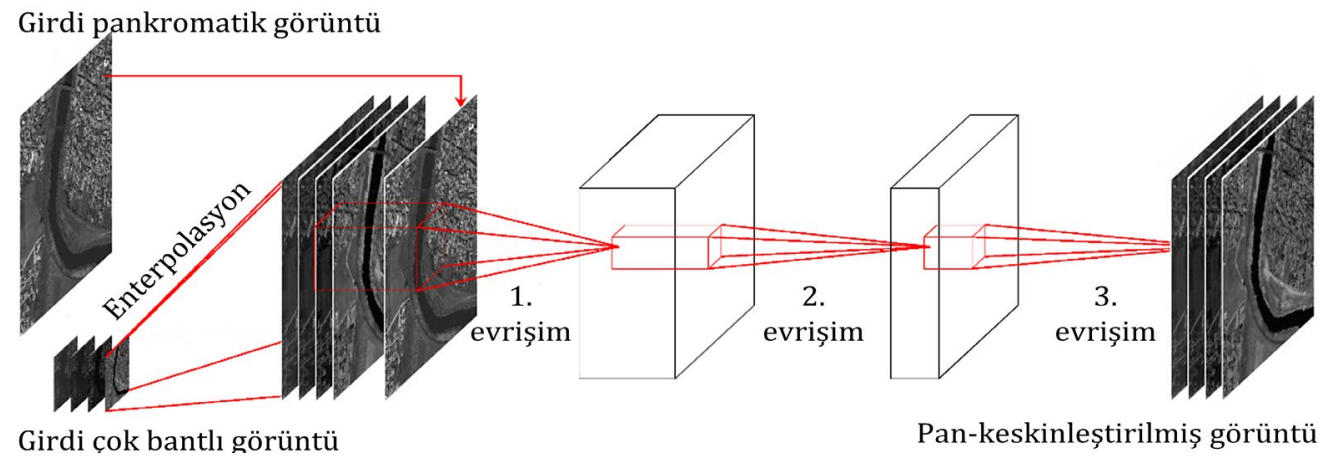

Şekil 6. Derin öğrenme tabanlı pan-keskinleştirme yöntemlerinin çalışma prensibi (Masi vd., 2016).

\subsubsection{Metasezgisel optimizasyon tabanll yöntemler}

Pan-keskinleştirme işleminde başarının sağlanabilmesi için girdi çok bantlı görüntünün ve pankromatik görüntünün pan-keskinleştirilmiş görüntüye katkılarının yüksek doğrulukla belirlenmesi gerekmektedir (Yilmaz vd., 2020). Literatürdeki yöntemlerin çoğu bu katkı oranlarını başarılı bir şekilde belirleyemediklerinden dolayı pan-keskinleştirilmiş görüntülerde ya spektral ya da uzamsal detay bozulmaları meydana gelmektedir. Son yıllarda geliştirilen bazı yaklaşımlar girdi görüntülerin pankeskinleştirilmiş görüntüye katkılarını belirlemek için metasezgisel optimizasyon algoritmalarından faydalanmaktadır. Bu algoritmalar çok geniş ve karmaşık yapıdaki arama uzaylarında dahi optimum çözüm adaylarını bulmakta oldukça başarılı olduklarından dolayı dikkat çekici pankeskinleştirme performansları sunmaktadırlar. Yilmaz vd., (2021) SVR yönteminin performansını Genetik Algoritma (GA) (Holland, 1975) yardımıyla iyileştirirken, Serifoglu Yilmaz vd., (2019) aynı yöntemin performansını son yılların kararlı ve güçlü arama algoritmalarından olan Ortak Yaşam Arama (Symbiotic Organisms Search - SOS) (Cheng ve Prayogo, 2014) algoritması ile iyileştirmişlerdir. Yilmaz vd., (2008), bir diğer bileşen değişimi tabanlı yöntem olan GS yöntemi ile elde edilen pan-keskinleştirilmiş görüntülerin optimize edilmesi amaciyla GA' dan faydalanmışlardır. Serifoglu Yilmaz vd., (2020) hibrit bir pan-keskinleştirme yöntemi olan IHSDWT yönteminin neden olduğu renk ve uzamsal detay bozulmalarını en aza indirmek için SOS algoritmasından faydalanmışlardır. Serifoglu Yilmaz (2020), SOS algoritmasının çok amaçlı versiyonu olan ve Pareto analizini (Censor, 1977) kullanan Çok Amaçı SOS (Multi-Objective SOS MOSOS) algoritmas1 ile SVR ve IHS-DWT yöntemlerini hem spektral hem de uzamsal detay yapılarını koruyabilmeleri için optimize etmiştir. Yilmaz (2021) ise Domine Edilemeyen Stralamalı GA-II (Non-Dominated Sorting Genetic
Algorithm-II - NSGA-II) (Deb vd., 2002) algoritmasinı kullanarak GS ve SVR yöntemlerinde spektral ve uzamsal detay kalitesi arasındaki optimum dengeyi sağlamıștır. Pankeskinleştirmeye çok amaçlı bir optimizasyon problemiymiş gibi yaklaşılması, birden fazla sonuç görüntünün elde edilmesini sağlamıştır. İhtiyaca göre spektral veya uzamsal detay yapılarının daha çok korunduğu ya da bu ikisi arasındaki dengenin sağlanabildiği pan-keskinleştirilmiş görüntüler sunabilmeleri çok amaçlı optimizasyon tabanlı yöntemlerin avantajları arasında görülmektedir (Serifoglu Yilmaz vd., 2020). Ancak özellikle çok amaçlı optimizasyon yöntemlerinin, çalışma alanı büyüdükçe optimum sonuca ulaşmaları uzun sürebilmektedir.

\section{Pan-keskinleştirmede doğruluk analizi}

Pan-keskinleştirme işlemi hataya oldukça açık bir işlem olduğundan pan-keskinleştirme ile elde edilen sonuç görüntülerin spektral kaliteleri ve uzamsal detay içerikleri kontrol edilmelidir. Literatürde, pan-keskinleştirme sonucunda elde edilen görüntülerin spektral ve uzamsal detay kalitelerinin bazen nicel olarak (Padwick vd., 2010; Vicinanza vd., 2015), bazen de hem nitel hem de nicel olarak incelendiği görülmektedir (Vivove vd., 2015; Serifoglu Yilmaz vd., 2019). Pankeskinleștirilmiş görüntülerin spektral kalitelerinin görsel olarak irdelenirken, bu görüntülerdeki arazi detaylarının renklerinin girdi çok bantlı görüntülerdeki renkler ile uyumlu olup olmadığ nitel olarak incelenir. Yüksek uyumluluğun olmas1, renk kalitesinin pan-keskinleştirmeden sonra korunduğunu göstermektedir. Uzamsal detay kalitesinin nitel olarak değerlendirilmesi için ise pan-keskinleştirilmiş görüntüdeki uzamsal detaylar (bina kenarı, yol kesişimi vb.) ile girdi pankromatik görüntüdeki uzamsal detayların uyumluluğu karşılaştırılır. Her iki görüntüdeki yüksek uyumluluk yüksek uzamsal detay kalitesine işaret eder. 
Nitel değerlendirme, kullanılan pan-keskinleştirme yöntemlerinin performansları hakkında genel bir bakış açısı sunmasına rağmen oldukça özneldir ve büyük ölçüde analistin bakış açısına ve kullanılan monitörün özelliklerine bağlıdır (Yilmaz vd., 2020). Ayrıca nitel değerlendirme esnasında insan gözüyle ayırt edilemeyecek bazı detaylar da gözden kaçabilmektedir (Serifoglu Yilmaz vd., 2020). $\mathrm{Bu}$ nedenle pan-keskinleştirilmiş görüntülerin spektral ve uzamsal detay kalitelerinin daha başarılı bir şekilde değerlendirilebilmesi için nicel kalite metriklerinden faydalanılmalıdır. $\mathrm{Bu}$ kalite metrikleri pan-keskinleştirilmiş görüntülerin spektral ve uzamsal detay kalitesini ölçerek kaliteyi belli sayılarla ifade etmektedirler. Her bir kalite metriğinin bir referans değeri bulunmaktadır. Herhangi bir pan-keskinleştirilmiş görüntü için hesaplanan metrik değeri referans değere ne kadar yakınsa spektral veya uzamsal detay kalitesi o kadar yüksektir. Pan-keskinleştirilmiş görüntülerin spektral kalitelerinin nicel metriklerle irdelenmesi için Wald vd., (1997) tarafindan önerilen protokolden sıklıkla faydalanılmaktadır (Alparone vd., 2008; Amro vd., 2011; Delleji vd., 2016; Dou, 2018; Serifoglu Yilmaz vd., 2019; Yilmaz vd., 2021). Bu protokole göre pan-keskinleştirilmiş bir görüntünün çözünürlüğü girdi çok bantl1 görüntünün çözünürlügüne kötüleştirildiğinde elde edilen görüntü, girdi çok bantlı görüntü ile aynı olmalıdır. Dolayısıyla kalite metrikleri girdi çok bantlı görüntü ile çözünürlüğü kötüleştirilen pankeskinleştirilmiş görüntü arasında hesaplanarak spektral kalite irdelenebilmektedir. Literatürdeki bazı çalışmalar ise spektral kalitenin irdelenebilmesi için girdi çok bantlı görüntünün çözünürlüğünün, girdi pankromatik görüntünün çözünürlüğüne çıkarılmasıyla elde edilen görüntünün referans olarak kullanılabileceğini ortaya koymuştur (Amro vd., 2011; Liu vd., 2015; Serifoglu Yilmaz vd., 2019). Uzamsal detay kalitesinin irdelenmesi için ise kalite metrikleri pan-keskinleştirilmiş görüntüler ile girdi pankromatik görüntüler arasında hesaplanmaktadır (Serifoglu Yilmaz vd., 2019; 2020; Yilmaz vd., 2020; 2021).

Pan-keskinleştirilmiş görüntülerin spektral kalitelerinin değerlendirilmesi için literatürde oldukça fazla sayıda kalite metriği tanımlanmıştır. Karesel Ortalama Hata (Root Mean Square Error RMSE) (Wald ve Ranchin, 2002), Bağıl Ortalama Spektral Hata (Relative Average Spectral Error RASE) (Ranchin ve Wald, 2000), Erreur Relative Globale Adimensionnelle De Synthése (ERGAS) (Wald, 2000), Spectral Angular Mapper (SAM) (Alparone vd., 2006) ve Spectral Information Divergence (SID) (Strait vd., 2008) metrikleri spektral kalitenin değerlendirilmesinde sıklıkla kullanılan konvansiyonel metriklerdendir. Pankeskinleştirilmiş görüntülerin spektral kalitesini ölçmek için kullanılan her bir metrik genelde farklı bir yaklaşım kullandığı için en iyi kalite metriğinin hangisi olduğuna dair bir fikir birliği yoktur (Yilmaz vd., 2021). Her bir kalite metriğinin kendine has avantajları ve dezavantajları vardır. $\mathrm{Bu}$ nedenle bir kalite metriği tarafından başarılı kabul edilen bir pan-keskinleştirme yöntemi, başka bir metrik tarafından başarısız sayılabilir. $\mathrm{Bu}$ gibi durumlarda farklı kalite metrik değerlerindeki trendler incelenerek pan-keskinleştirme performansı hakkında önemli ipuçları elde edilebilir (Yilmaz vd., 2021). Bu nedenledir ki literatürdeki çalışmaların birçoğu spektral kaliteyi irdelerken birden fazla kalite metriğinden faydalanmaktadır (Vivone vd., 2015; Masi vd., 2016; Serifoglu Yilmaz vd., 2019; 2020; Yilmaz vd., 2020; 2021; Jiang vd., 2020). Bilgi İçeriği Ağılıklı Yapısal Benzerlik (Information Content Weighted Structural Similarity - IW-SSIM) (Wang ve $\mathrm{Li}, 2011)$, Genel Görüntü Kalite İndeksi (Universal Image Quality Index - UIQI) (Wang ve Bovik, 2002), Çoklu Ölçekli Yapısal Benzerlik (Multi-Scale Structural Similarity - MS-SSIM) (Wang vd., 2003), Yapısal Benzerlik İndeksi (Structural Similarity Index - SSIM) (Wang vd., 2004) ve Spectral Residual Based Similarity (SRSIM) (Zhang ve Li, 2012) renk kalitesinin irdelenmesinde kullanılan bazı gelişmiş metriklerdendir.

Entropi (Bai vd., 2011), Korelasyon Katsayıs1 (KK) (Yilmaz vd., 2021) ve Uzamsal Korelasyon Katsayıs1 (Spatial Correlation Coefficient - SCC) (Zhou vd., 1998) metrikleri ise pankeskinleştirilmiş görüntülerin uzamsal detay kalitelerinin değerlendirilmesi için kullanılan bazı metriklerdendir. Bunlarla beraber, spektral kalitenin irdelenmesi için kullanılan SSIM, IWSSIM ve UIQI metrikleri uzamsal detay kalitesinin irdelenmesi için de kullanılabilir (Serifoglu Yilmaz vd., 2020; Yilmaz vd., 2021).

Pan-keskinleştirilmiş görüntülerin spektral ve uzamsal detay kalitelerinin girdi pankromatik görüntü boyutunda irdelenmesi için önerilen bazı kalite metrikleri de bulunmaktadır. Alparone vd., (2008) tarafindan önerilen Quality with no Reference (QNR) ve Aiazzi vd., (2014) tarafindan önerilen Hybrid QNR (HQNR) metrikleri bu amaçla en sık kullanılan metriklerdir. Her iki metrik de spektral ve uzamsal detay kalitesini iki ayrı kalite metriği ile ölçer ve bu iki kalite metriği bir formülde birleştirilerek pan-keskinleştirilmiş görüntünün genel kalitesi tek bir sayı ile ifade edilir. QNR metriği spektral kaliteyi $\mathrm{D}_{\lambda}$ metriği ile 
ölçerken, uzamsal detay kalitesini $\mathrm{D}_{\mathrm{S}}$ metriği ile ölçmektedir (Alparone vd., 2008). HQNR metriği ise spektral kaliteyi Khan vd., (2009) tarafindan önerilen metrikle ölçerken, uzamsal detay kalitesini ise Alparone vd., (2008) tarafindan önerilen $D_{S}$ metriği ile ölçmektedir (Aiazzi vd., 2014). ERGAS, SSIM, IW-SSIM, UIQI, SR-SIM, MS-SSIM, KK, SAM, $\mathrm{D}_{\lambda}, \mathrm{D}_{\mathrm{S}}$, QNR ve HQNR metriklerinin formülleri ve optimum değerleri Tablo 1' de verilmiştir.

Tablo 1. Bazı kalite metriklerinin formülleri

\begin{tabular}{|c|c|}
\hline Formül & \multirow{2}{*}{$\begin{array}{c}\text { Optimum değer } \\
0\end{array}$} \\
\hline$E R G A S=100 \frac{h}{o} \sqrt{\frac{1}{K}} \sum_{k=1}^{K}\left(\frac{R M S E_{k}}{\mu\left(M S_{k}\right)}\right)^{2}$ & \\
\hline$S S I M=\frac{\left(2 \mu_{x} \mu_{y}+C_{1}\right)\left(2 \sigma_{x y}+C_{2}\right)}{\left(\mu_{x}^{2}+\mu_{y}^{2}+C_{1}\right)\left(\sigma_{x}^{2}+\sigma_{y}^{2}+C_{2}\right)}$ & 1 \\
\hline $\begin{array}{c}I W-\operatorname{SSIM}_{j}=\frac{\sum_{i} w_{j, i} c\left(x_{j, i}, y_{j, i}\right) s\left(x_{j, i}, y_{j, i}\right)}{\sum w_{j, i}} \\
I W-\operatorname{SSIM}=\prod\left(I W-S S I M_{j}\right)^{B_{j}}\end{array}$ & 1 \\
\hline$U I Q I=\frac{4 \mu_{x} \mu_{y} \sigma_{x y}}{\left(\mu_{x}^{2}+\mu_{y}^{2}\right)\left(\sigma_{x}^{2}+\sigma_{y}^{2}\right)}$ & 1 \\
\hline$S R-S I M=\frac{\sum_{x \in \Omega} S(x) \cdot R_{m}(x)}{\sum_{x \in \Omega} R_{m}(x)}$ & 1 \\
\hline$M S-S S I M=\left[l_{M}(x, y)\right]^{\alpha_{M}} \cdot \prod_{j=1}\left[c_{j}(x, y)\right]^{\beta_{j}}\left[s_{j}(x, y)\right]^{\gamma_{j}}$ & 1 \\
\hline$K K=\frac{\sum_{m, n}\left(C, B_{m n}-\mu(C, B)\right)\left(P_{m n}-\mu(P)\right)}{\sqrt{\left(\sum_{m, n}\left(C, B_{m n}-\mu(C, B)\right)^{2}\left(\sum_{m, n}\left(P_{m n}-\mu(P)\right)^{2}\right)\right.}}$ & 1 \\
\hline$S A M \triangleq \arccos \left(\frac{\langle x, y\rangle}{\|x\|_{2} \cdot\|y\|_{2}}\right)$ & 0 \\
\hline$D_{\lambda}=\sqrt{\frac{1}{K(K-1)} \sum_{b=1}^{K} \sum_{h=1, h \neq b}^{K}\left|U I Q I\left(C ̧ B_{b}, C ̧ B_{h}\right)-U I Q I\left(P_{b}, P_{h}\right)\right|}$ & 0 \\
\hline$D_{S}=\sqrt{\frac{1}{K} \sum_{b=1}^{K}\left|U I Q I\left(C B_{b}, P A N_{L}\right)-U I Q I\left(P_{b}, P A N\right)\right|}$ & 0 \\
\hline$D_{\lambda}^{(K)}=1-Q\left(P_{L}, C ̧ B\right)$ & 0 \\
\hline$Q N R=\left(1-D_{\lambda}\right) \cdot\left(1-D_{S}\right)$ & 1 \\
\hline$H Q N R=\left(1-D_{\lambda}^{(K)}\right) \cdot\left(1-D_{s}\right)$ & 1 \\
\hline
\end{tabular}

Bu tabloda, ÇB girdi çok bantlı görüntüyü; $P A N$ girdi pankromatik görüntüyü; $P$ pan-keskinleştirilmiş görüntüyü; $x$ girdi çok bantlı görüntüdeki bir piksel vektörünü; $y$ girdi pankromatik görüntüdeki bir piksel vektörünü; $\mu$ ortalamayı; $\sigma$ varyansı; $h / o$ girdi görüntülerin çözünürlüklerinin oranını; $K$ toplam bant sayısını; $C_{1}=\left(Y_{1} L\right)^{2}$ ve $C_{2}=\left(Y_{2} L\right)^{2}$ (Y küçük bir sabit ve $L$ görüntünün radyometrik çözünürlüğü); $\propto_{M}, \beta_{j}$ ve $\gamma_{j}$ bileşenlerin etkilerini kontrol eden katsayıları; $S(x)$ yerel benzerliği; $\Omega$ konum uzayını; $R_{m}(x)=\max \left(R_{1}(x), R_{2}(x)\right), S(x)$ değerinin ağırlığını; $w$ bilgi içeriğini kontrol eden ağırlığı; $D_{\lambda}^{(K)}$ Khan vd., (2009) tarafından renk kalitesini ölçmek için önerilen metriği ve $Q$ ise dört bantlı görüntüler için Q4 metriğini (Alparone vd., 2004), sekiz bantlı görüntüler için ise Q8 metriğini (Garzelli ve Nencini, 2009) ifade etmektedir.

\section{Sonuç}

Pan-keskinleştirme, uzamsal detay kalitesi yüksek çok bantlı görüntüler üretilebilmesi için önemli bir süreçtir. Günümüze kadar literatürde oldukça fazla sayıda pan-keskinleştirme yönteminin tanıtılmış olması, kullanıcıları hangi yöntemin hangi durumlarda kullanılabileceği konusunda tereddüte düşürmektedir. Bu nedenle bu çalışma kullanıcıları mevcut pan-keskinleştirme yöntemleri ve pankeskinleştirme sonucu elde edilen görüntülerin spektral ve uzamsal detay kalitelerinin nasıl irdelenebileceği hakkında bilgilendirmeyi amaçlamaktadır.

Değerlendirmeler, yüksek uzamsal detay kalitesinin gerektiği durumlarda renk tabanlı ve bileşen değişimi tabanlı yöntemlerin 
kullanılabileceğini, yüksek spektral doğruluğa ihtiyaç duyulan durumlarda ise çoklu çözünürlük analizi tabanlı, derin öğrenme tabanlı ve ayrık temsil tabanlı yöntemlerin kullanılabileceğini ortaya koymaktadır. Spektral ve uzamsal detay kalitesi arasındaki optimum dengenin kurulması gereken durumlarda ise metasezgisel arama algoritmalarına dayanan optimizasyon yöntemlerinden faydalanılabilineceği söylenebilir. Metasezgisel optimizasyon tabanlı yöntemlerin bir diğer avantaj1 da pan-keskinleştirme işlemini otomatikleştirerek kullanıcı müdahalesinden kaynaklanan pan-keskinleştirme hatalarını en aza indirmesidir.

\section{Kaynaklar}

Addesso, P., Conte, R., Longo, M., Restaino, R. and Vivone, G. (2012). A pansharpening algorithm based on genetic optimization of Morphological Filters. International Geoscience and Remote Sensing Symposium, Munich, Germany.

Aiazzi, B., Alparone, L., Baronti, S., Carlà, R., Garzelli, A. and Santurri, L. (2014). Full-scale assessment of pansharpening methods and data products. Image and Signal Processing for Remote Sensing $X X$, vol. 9244, p. 924402, Amsterdam, Netherlands.

https://doi.org/10.1117/12.2067770.

Aiazzi, B., Alparone, L., Baronti, S., Garzelli, A. and Selva, M. (2006). MTF-tailored multiscale fusion of high-resolution MS and Pan imagery. Photogrammetric Engineering \& Remote Sensing, 72(5), 591-596. https://doi.org/10.14358/PERS.72.5.591.

Aiazzi, B., Baronti, S. and Selva, M. (2007). Improving component substitution pansharpening through multivariate regression of $\mathrm{MS}+$ Pan data. IEEE Transactions on Geoscience and Remote Sensing, 45(10), 3230-3239. https://doi.org/10.1109/TGRS.2007.901007.

Alparone, L., Aiazzi, B., Baronti, S., Garzelli, A. and Nencini, F. (2006). Information-Theoretic Image Fusion Assessment without Reference. ESAEUSC 2006: Image Information Mining for Security and Intelligence, Torrejon Air Base, Madrid, Spain.

Alparone, L., Aiazzi, B., Baronti, S., Garzelli, A., Nencini, F. and Selva, M. (2008). Multispectral and panchromatic data fusion assessment without reference. Photogrammetric Engineering \& Remote Sensing, 74(2), 193-200. https://doi.org/10.14358/PERS.74.2.193.

Alparone, L., Baronti, S., Garzelli, A. and Nencini, F. (2004). A global quality measurement of pansharpened multispectral imagery. IEEE
Geoscience and Remote Sensing Letters, 1(4), 313-317.

https://doi.org/10.1109/LGRS.2004.836784.

Amro, I., Mateos, J., Vega, M., Molina, R. and Katsaggelos, A. K. (2011). A survey of classical methods and new trends in pansharpening of multispectral images. EURASIP Journal on Advances in Signal Processing, 2011(1), 1-22. https://doi.org/10.1186/1687-6180-2011-79.

Bai, X., Zhou, F. and Xue, B. (2011). Fusion of infrared and visual images through region extraction by using multi scale center-surround top-hat transform. Optics Express, 19(9), 8444-8457. https://doi.org/10.1364/OE.19.008444.

Benzenati, T., Kallel, A. and Kessentini, Y. (2020). Two stages pan-sharpening details injection approach based on very deep residual networks. IEEE Transactions on Geoscience and Remote Sensing, 59(6), 4984-4992. https://doi.org/10.1109/TGRS.2020.3019835.

Censor, Y. (1977). Pareto optimality in multiobjective problems. Applied Mathematics and Optimization, 4(1), 41-59. https://doi.org/10.1007/BF01442131.

Cheng, M. Y. and Prayogo, D. (2014). Symbiotic organisms search: a new metaheuristic optimization algorithm. Computers \& Structures, 139, 98-112. https://doi.org/10.1016/j.compstruc.2014.03.007

Crippen, R. E. (1989). A simple spatial filtering routine for the cosmetic removal of scan-line noise from Landsat TM P-tape imagery. Photogrammetric Engineering and Remote Sensing, 55(3), 327331.

de Béthune, S., Muller, F. and Binard, M. (1997). Adaptive intensity matching filters: a new tool for multiresolution data fusion. Multi-Sensor Systems and Data Fusion for Telecommunications, Remote Sensing and Radar, Lisbon, Portugal.

Deb, K., Pratap, A., Agarwal, S. and Meyarivan, T. A. M. T. (2002). A fast and elitist multiobjective genetic algorithm: NSGA-II. IEEE Transactions on Evolutionary Computation, 6(2), 182-197. https://doi.org/10.1109/4235.996017.

Delleji, T., Kallel, A. and Ben Hamida, A. (2016). Iterative scheme for MS image pansharpening based on the combination of multi-resolution decompositions. International Journal of Remote Sensing, 37(24), 6041-6075. https://doi.org/10.1080/01431161.2016.1249303 
Dou, W. (2018). Image degradation for quality assessment of pan-sharpening methods. Remote Sensing, 10(1),

154.

https://doi.org/10.3390/rs10010154.

Ehlers, M. (2004). Spectral characteristics preserving image fusion based on Fourier domain filtering. In Remote sensing for environmental monitoring, GIS applications, and geology IV (vol. 5574, pp. 1-13). International Society for Optics and Photonics. https://doi.org/10.1117/12.565160.

El-Samie, F. E. A., Hadhoud, M. M. and El-Khamy, S. E. (2012). Image super-resolution and applications. CRC press.

Farwell, L. S., Gudex-Cross, D., Anise, I. E., Bosch, M. J., Olah, A. M., Radeloff, V. C., Razenkova, E., Rogova, N., Silviera, E. M. O., Smith, M. M. and Pidgeon, A. M. (2021). Satellite image texture captures vegetation heterogeneity and explains patterns of bird richness. Remote Sensing of Environment, 253, 112175. https://doi.org/10.1016/j.rse.2020.112175.

Fei, R., Zhang, J., Liu, J., Du, F., Chang, P., \& Hu, J. (2019). Convolutional sparse representation of injected details for pansharpening. IEEE Geoscience and Remote Sensing Letters, 16(10), 1595-1599.

https://doi.org/10.1109/LGRS.2019.2904526.

Garzelli, A. and Nencini, F. (2006). PAN-sharpening of very high resolution multispectral images using genetic algorithms. International Journal of Remote Sensing, 27(15), 3273-3292. https://doi.org/10.1080/01431160600554991.

Garzelli, A. and Nencini, F. (2009). Hypercomplex quality assessment of multi/hyperspectral images. IEEE Geoscience and Remote Sensing Letters, 6(4), 662-665. https://doi.org/10.1109/LGRS.2009.2022650.

Ghahremani, M., Liu, Y., Yuen, P. and Behera, A. (2019). Remote sensing image fusion via compressive sensing. ISPRS Journal of Photogrammetry and Remote Sensing, 152, 3448.

https://doi.org/10.1016/j.isprsjprs.2019.04.001.

Ghassemian, H. (2016). A review of remote sensing image fusion methods. Information Fusion, 32, 75-89.

https://doi.org/10.1016/j.inffus.2016.03.003.

González-Audícana, M., Saleta, J. L., Catalán, R. G. and García, R. (2004). Fusion of multispectral and panchromatic images using improved IHS and PCA mergers based on wavelet decomposition. IEEE Transactions on Geoscience and Remote sensing, 42(6),

1291-1299. https://doi.org/10.1109/TGRS.2004.825593.
Gungor, O. (2008). Multi sensor multi resolution image fusion. PhD Thesis, Purdue University, USA.

Hallabia, H., Kallel, A. and Hamida, A. B. (2014). Image pansharpening: Comparison of methods based on multiresolution analysis and component substitution. IEEE 1st International Conference on Advanced Technologies for Signal and Image Processing (ATSIP), Sousse, Tunisia. https://doi.org/10.1109/ATSIP.2014.6834602.

Hallada, W. A. and Cox, S. (1983). Image sharpening for mixed spatial and spectral resolution satellite systems. 17th International Symposium on Remote Sensing of Environment (pp. 1023-1032), Ann Arbor, MI.

Haydn, R., Dalke, G. W., Henkel, J. and Bare, J. E. (1982). Application of the IHS color transform to the processing of multisensor data and image enhancement. International Symposium on Remote Sensing of Environment, First Thematic Conference: 'Remote Sensing of Arid and Semiarid Lands' (pp. 599-616), Cairo, Egypt.

Holland, H. (1975). Adaptation in Natural and Artificial Systems. Ann Arbor (MI), The University of Michigan Press.

Jiang, C., Zhang, H., Shen, H. and Zhang, L. (2012). A practical compressed sensing-based pansharpening method. IEEE Geoscience and Remote Sensing Letters, 9(4), 629-633. https://doi.org/10.1109/LGRS.2011.2177063.

Jiang, M., Shen, H., Li, J., Yuan, Q. and Zhang, L. (2020). A differential information residual convolutional neural network for pansharpening. ISPRS Journal of Photogrammetry and Remote Sensing, 163, 257-271. https://doi.org/10.1016/j.isprsjprs.2020.03.006.

Jinju, J., Santhi, N., Ramar, K. and Bama, B. S. (2019). Spatial frequency discrete wavelet transform image fusion technique for remote sensing applications. Engineering Science and Technology, an International Journal, 22(3), 715-726.

https://doi.org/10.1016/j.jestch.2019.01.004.

Kamir, E., Waldner, F. and Hochman, Z. (2020). Estimating wheat yields in Australia using climate records, satellite image time series and machine learning methods. ISPRS Journal of Photogrammetry and Remote Sensing, 160, 124135. https://doi.org/10.1016/j.isprsjprs.2019.11.008.

Khan, M. M., Alparone, L. and Chanussot, J. (2009). Pansharpening quality assessment using the modulation transfer functions of instruments. IEEE Transactions on Geoscience and Remote Sensing, 47(11), 3880-3891. https://doi.org/10.1109/TGRS.2009.2029094. 
Khan, M. M., Chanussot, J., Condat, L. and Montanvert, A. (2008). Indusion: Fusion of multispectral and panchromatic images using the induction scaling technique. IEEE Geoscience and Remote Sensing Letters, 5(1), 98-102. https://doi.org/10.1109/LGRS.2007.909934.

Khatancharoen, C., Tsuyuki, S., Bryanin, S. V., Sugiura, K., Seino, T., Lisovsky, V. V., Borisova, I. G. and Wada, N. (2021). Long-Time Interval Satellite Image Analysis on Forest-Cover Changes and Disturbances Around Protected Area, Zeya State Nature Reserve, in The Russian Far East. Remote Sensing, 13(7), 1285. https://doi.org/10.3390/rs13071285.

Klonus, S. and Ehlers, M. (2007). Image fusion using the Ehlers spectral characteristics preservation algorithm. GIScience \& Remote Sensing, 44(2), 93-116. https://doi.org/10.2747/15481603.44.2.93.

Kwarteng, P. and Chavez, A. (1989). Extracting spectral contrast in Landsat Thematic Mapper image data using selective principal component analysis. Photogrammetric Engineering and Remote Sensing, 55(1), 339-348.

Laben, C. A. and Brower, B. V. (2000). Process for enhancing the spatial resolution of multispectral imagery using pan-sharpening. U.S. Patent No. $6,011,875$.

Li, S. and Yang, B. (2011). A new pan-sharpening method using a compressed sensing technique. IEEE Transactions on Geoscience and Remote Sensing, 49(2), 738-746. https://doi.org/10.1109/TGRS.2010.2067219.

Liu, J. G. (2000). Smoothing filter-based intensity modulation: A spectral preserve image fusion technique for improving spatial details. International Journal of Remote Sensing, 21(18), 3461-3472. https://doi.org/10.1080/014311600750037499.

Liu, J., Huang, J., Liu, S., Li, H., Zhou, Q. and Liu, J. (2015). Human visual system consistent quality assessment for remote sensing image fusion. ISPRS Journal of Photogrammetry and Remote Sensing, 105, 79-90. https://doi.org/10.1016/j.isprsjprs.2014.12.018.

Liu, X., Zhang, Q., Li, Y., Tan, Z. and Werner, A. D. (2020). Satellite image-based investigation of the seasonal variations in the hydrological connectivity of a large floodplain (Poyang Lake, China). Journal of Hydrology, 585, 124810. https://doi.org/10.1016/j.jhydrol.2020.124810.

Masi, G., Cozzolino, D., Verdoliva, L. and Scarpa, G. (2016). Pansharpening by convolutional neural networks. Remote Sensing, 8(7), 594. https://doi.org/10.3390/rs8070594.
Munechika, C. K., Warnick, J. S., Salvaggio, C. and Schott, J. R. (1993). Resolution enhancement of multispectral image data to improve classification accuracy. Photogrammetric Engineering and Remote Sensing, 59(1), 67-72.

Núñez, J., Otazu, X., Fors, O., Prades, A., Pala, V. and Arbiol, R. (1999). Multiresolution-based image fusion with additive wavelet decomposition. IEEE Transactions on Geoscience and Remote sensing, 37(3), https://doi.org/10.1109/36.763274.

Otazu, X., González-Audícana, M., Fors, O. and Núñez, J. (2005). Introduction of sensor spectral response into image fusion methods. Application to wavelet-based methods. IEEE Transactions on Geoscience and Remote Sensing, 43(10), 23762385.

https://doi.org/10.1109/TGRS.2005.856106.

Ozcelik, F., Alganci, U., Sertel, E. and Unal, G. (2020). Rethinking CNN-based pansharpening: Guided colorization of panchromatic images via GANS. IEEE Transactions on Geoscience and Remote Sensing, 59(4), 3486-3501. https://doi.org/10.1109/TGRS.2020.3010441.

Padwick, C., Deskevich, M., Pacifici, F. and Smallwood, S. (2010). WorldView-2 pansharpening. ASPRS 2010 Annual Conference (pp. 1-14), San Diego, CA, USA.

Pandit, V. R. and Bhiwani, R. J. (2020). Multispectral to Panchromatic Image Fusion Based on Morphological Extended-Half-Gradient. Journal of the Indian Society of Remote Sensing, 48(6), 945-957. https://doi.org/10.1007/s12524-02001127-2.

Pohl, C. and van Genderen, J. (2016). Remote sensing image fusion: A practical guide. Crc Press.

Pohl, C. and van Genderen, J. L. (1998). Review article multisensor image fusion in remote sensing: concepts, methods and applications. International Journal of Remote Sensing, 19(5), 823-854.

https://doi.org/10.1080/014311698215748.

Ranchin, T. and Wald, L. (2000). Fusion of high spatial and spectral resolution images: The ARSIS concept and its implementation. Photogrammetric Engineering and Remote Sensing, 66(1), 49-61.

Restaino, R., Vivone, G., Dalla Mura, M. and Chanussot, J. (2015). A pansharpening algorithm based on morphological filters. In International Symposium on Mathematical Morphology and its Applications to Signal and Image Processing (pp. 98-109). Springer, Cham. 
Restaino, R., Vivone, G., Dalla Mura, M. and Chanussot, J. (2016). Fusion of multispectral and panchromatic images based on morphological operators. IEEE Transactions on Image Processing, 25(6), 2882-2895. https://doi.org/10.1109/TIP.2016.2556944.

Schowengerdt, R. A. (1980). Reconstruction of multispatial, multispectral image data using spatial frequency content. Photogrammetric Engineering and Remote Sensing, 46(10), 13251334.

Serifoglu Yilmaz, C. (2020). Metaheuristic pansharpening based on symbiotic organisms search optimization. $\mathrm{PhD}$ Thesis, Karadeniz Technical University, Trabzon.

Serifoglu Yilmaz, C., Yilmaz, V. and Güngör, O. (2020). On the use of the SOS metaheuristic algorithm in hybrid image fusion methods to achieve optimum spectral fidelity. International Journal of Remote Sensing, 41(10), 3993-4021. https://doi.org/10.1080/01431161.2019.1711244

Serifoglu Yilmaz, C., Yilmaz, V., Gungor, O. and Shan, J. (2019). Metaheuristic pansharpening based on symbiotic organisms search optimization. ISPRS Journal of Photogrammetry and Remote Sensing, 158, 167-187. https://doi.org/10.1016/j.isprsjprs.2019.10.014.

Shi, Y. (2018). A new pansharpening algorithm using morphological lifting transform. IEEE $3 r d$ International Conference on Signal and Image Processing (ICSIP) (pp. 250-254), Shenzhen, China.

https://doi.org/10.1109/SIPROCESS.2018.8600 445.

Siddiqui, Y. (2003). The modified IHS method for fusing satellite imagery. ASPRS 2003 Annual Conference (pp. 5-9), Anchorage, Alaska.

Strait, M., Rahmani, S. and Markurjev, D. (2008). Evaluation of Pan-Sharpening Methods. UCLA Department of Mathematics.

Vicinanza, M. R., Restaino, R., Vivone, G., Dalla Mura, M. and Chanussot, J. (2015). A pansharpening method based on the sparse representation of injected details. IEEE Geoscience and Remote Sensing Letters, 12(1), 180-184. https://doi.org/10.1109/LGRS.2014.2331291.

Vivone, G., Alparone, L., Chanussot, J., Dalla Mura, M., Garzelli, A., Licciardi, G. A., Restaino, R. and Wald, L. (2015). A critical comparison among pansharpening algorithms. IEEE Transactions on Geoscience and Remote Sensing, 53(5), 25652586.

https://doi.org/10.1109/TGRS.2014.2361734.
Vivone, G., Restaino, R., Dalla Mura, M., Licciardi, G. and Chanussot, J. (2013). Contrast and errorbased fusion schemes for multispectral image pansharpening. IEEE Geoscience and Remote Sensing Letters, 11(5), 930-934. https://doi.org/10.1109/LGRS.2013.2281996.

Wald, L. (2000). Quality of High Resolution Synthesized Images: Is There a Simple Criterion? 3rd Conference Fusion Of Earth Data: Merging Point Measurements, Raster Maps and Remotely Sensed Images (pp. 99-103), Sophia Antipolis, France.

Wald, L. and Ranchin, T. (2002). Liu'Smoothing filterbased intensity modulation: A spectral preserve image fusion technique for improving spatial details'. International Journal of Remote Sensing, 23(3), 593-597. https://doi.org/10.1080/01431160110088772.

Wald, L., Ranchin, T. and Mangolini, M. (1997). Fusion of satellite images of different spatial resolutions: Assessing the quality of resulting images. Photogrammetric Engineering and Remote Sensing, 63(6), 691-699.

Wang, F., Lu, X., Mei, S., Su, Y., Zhen, Z., Zou, Z., Zhang, X., Yin, R., Duic, N., Shafie-khah, M. and Catalão, J. P. S. (2021). A Satellite Image Data based Ultra-short-term Solar PV Power Forecasting Method Considering Cloud Information from Neighboring Plant. Energy, 121946 https://doi.org/10.1016/j.energy.2021.121946.

Wang, Z. and Bovik, A. C. (2002). A universal image quality index. IEEE Signal Processing Letters, 9(3), 81-84. https://doi.org/10.1109/97.995823.

Wang, Z. and Li, Q. (2011). Information content weighting for perceptual image quality assessment. IEEE Transactions on Image Processing, 20(5), 1185-1198. https://doi.org/10.1109/TIP.2010.2092435.

Wang, Z., Bovik, A. C., Sheikh, H. R. and Simoncelli, E. P. (2004). Image quality assessment: from error visibility to structural similarity. IEEE Transactions on Image Processing, 13(4), 600612. https://doi.org/10.1109/TIP.2003.819861.

Wang, Z., Simoncelli, E. P. and Bovik, A. C. (2003). Multiscale structural similarity for image quality assessment. 37th IEEE Asilomar Conference on Signals, Systems \& Computers (pp. 1398-1402), Pacific Grove, CA, USA. https://doi.org/10.1109/ACSSC.2003.1292216.

Xing, Y., Wang, M., Yang, S. and Jiao, L. (2018). Pansharpening via deep metric learning. ISPRS Journal of Photogrammetry and Remote 
Sensing, 145,

165-183. https://doi.org/10.1016/j.isprsjprs.2018.01.016.

Xing, Y., Wang, M., Yang, S. and Zhang, K. (2018). Pansharpening with multiscale geometric support tensor machine. IEEE Transactions on Geoscience and Remote Sensing, 56(5), 25032517.

https://doi.org/10.1109/TGRS.2017.2742002.

Yang, C., Zhan, Q., Liu, H. and Ma, R. (2018). An IHSbased pan-sharpening method for spectral fidelity improvement using ripplet transform and compressed sensing. Sensors, 18(11), 3624. https://doi.org/10.3390/s18113624.

Yilmaz, V. (2021). A Non-Dominated Sorting Genetic Algorithm-II-based approach to optimize the spectral and spatial quality of component substitution-based pansharpened images. Concurrency and Computation: Practice and Experience, 33(5), e6030. https://doi.org/10.1002/cpe.6030.

Yilmaz, V. and Gungor, O. (2016a). Determining the optimum image fusion method for better interpretation of the surface of the Earth. Norsk Geografisk Tidsskrift-Norwegian Journal of Geography, 70(2), 69-81. https://doi.org/10.1080/00291951.2015.1126761

Yilmaz, V. and Gungor, O. (2016b). Fusion of very high-resolution UAV images with criteria-based image fusion algorithm. Arabian Journal of Geosciences, $9(1)$, $1-16$. https://doi.org/10.1007/s12517-015-2109-8.

Yilmaz, V., Serifoglu Yilmaz, C. and Gungor, O. (2021). Genetic algorithm-based synthetic variable ratio image fusion. Geocarto International, 36(9), 989-1006. https://doi.org/10.1080/10106049.2019.1629649
Yilmaz, V., Serifoglu Yilmaz, C., Güngör, O. and Shan, J. (2020). A genetic algorithm solution to the gram-schmidt image fusion. International Journal of Remote Sensing, 41(4), 1458-1485. https://doi.org/10.1080/01431161.2019.1667553

Yin, H. (2015). Sparse representation based pansharpening with details injection model. Signal Processing, 113, 218-227. https://doi.org/10.1016/j.sigpro.2014.12.017.

Yusuf, Y., Sri Sumantyo, J. T. and Kuze, H. (2013). Spectral information analysis of image fusion data for remote sensing applications. Geocarto International, 28(4), 291-310. https://doi.org/10.1080/10106049.2012.692396.

Zhang, L. and Li, H. (2012). SR-SIM: A fast and high performance IQA index based on spectral residual. 19th IEEE International Conference on Image Processing (pp. 1473-1476), Orlando, FL, USA.

https://doi.org/10.1109/ICIP.2012.6467149.

Zhang, L., Li, W., Shen, L. and Lei, D. (2020). Multilevel dense neural network for pansharpening. International Journal of Remote Sensing, 41(18), 7217-7232. https://doi.org/10.1080/01431161.2020.1755474

Zhou, J., Civco, D. L. and Silander, J. A. (1998). A wavelet transform method to merge Landsat TM and SPOT panchromatic data. International Journal of Remote Sensing, 19(4), 743-757. https://doi.org/10.1080/014311698215973.

Zhu, X. X. and Bamler, R. (2013). A sparse image fusion algorithm with application to pansharpening. IEEE Transactions on Geoscience and Remote Sensing, 51(5), 2827-2836. https://doi.org/10.1109/TGRS.2012.2213604. 